Article

\title{
Beyond Limitations of Current Behaviour Change Apps for Sustainable Mobility: Insights from a User-Centered Design and Evaluation Process
}

\author{
Francesca Cellina ${ }^{1, *(\mathbb{D})}$, Dominik Bucher ${ }^{2}{ }^{\mathbb{D}}$, José Veiga Simão ${ }^{1}$, Roman Rudel ${ }^{1}$ and \\ Martin Raubal 2 (D) \\ 1 Insitute for Applied Sustainability to the Built Environment, SUPSI, Via Trevano, \\ 6952 Canobbio, Switzerland; jose.simao@supsi.ch (J.V.S.); roman.rudel@supsi.ch (R.R.) \\ 2 Institute of Cartography and Geoinformation, ETH Zurich, Stefano-Franscini-Platz 5, \\ 8093 Zürich, Switzerland; dobucher@ethz.ch (D.B.); mraubal@ethz.ch (M.R.) \\ * Correspondence: francesca.cellina@supsi.ch; Tel.: +41-058-666-6261
}

Received: 22 March 2019; Accepted: 11 April 2019; Published: 16 April 2019

\begin{abstract}
How can we encourage people to make sustainable mobility choices, reducing car dependency and the related $\mathrm{CO}_{2}$ emissions and energy consumption? Taking advantage of the wide availability of smartphone devices, we designed GoEco!, an application (app) exploiting automatic mobility tracking, eco-feedback, social comparison and gamification elements to persuade individuals to change their mode of transport. The app features and contents are grounded in the transtheoretical model for behaviour change and were designed to avoid over-reliance on "one-size-fits-all", simplistic point-based systems. The GoEco! app was designed in a user centred approach and was field-tested in Switzerland in a three-month experiment involving around 150 voluntary users. In this paper, we present the app's features and comment on their evaluation from the perspective of the field-testers. The insights we collected through an online questionnaire and individual interviews allowed us to develop recommendations for similar persuasive apps and to identify open challenges for the future. In particular, we recommend to endow such apps with multi-modal travel planning components and features evoking the feeling of belonging to a community, that provide support and helping relationships.
\end{abstract}

Keywords: persuasion; eco-feedback; gamification; app; mobility patterns; user-centered design

\section{Introduction}

To counteract local and global problems associated with the deep-rooted car dependency [1-3] and lock-in in the "automobility system" [4] currently affecting most urban areas, cities seek to improve mobility alternatives to cars and promote the use of a mix of transport modes, facilitating the break of car-dependent habits [5] and encouraging a higher uptake of public transport and soft mobility transport modes. Leveraging cognitive-motivational aspects [6], voluntary travel behaviour change programmes [7] were introduced, targeting a change in individual mobility choices [8]. The growing diffusion of Information and Communication Technologies (ICTs) in the transportation field $[9,10]$ and the parallel emergence of smart [11] and responsive [12] city programmes offer opportunities to design novel cognitive-motivational tools supporting individuals in the adoption of more sustainable mobility patterns. Particularly, under the influence of the captology framework (the study of Computers As Persuasive Technologies, CAPT) [13], a fast growing body of literature is exploring the potential of coupling persuasion techniques with ICTs, and smartphone apps were identified as very promising tools, due to their capability to provide users with real-time and bi-directional interaction possibilities. 


\subsection{Persuasion for Behaviour Change by Smartphone Apps}

Smartphone apps persuading users to engage in more sustainable behaviour were at first developed to promote electricity and water savings, accompanying the roll-out of smart meter devices to measure real-time electricity and water consumption (among others, see [14-28]). Such apps provide users with feedback on consequences of their choices (usually, in terms of energy consumption and $\mathrm{CO}_{2}$ emissions), invite them to define personal goals for change, engage in challenges and compare their performances with other users, often also exploiting the users' social network relationships [29-38]. Frequently, such apps also exploit gamification, which is usually defined as "the use of game elements in non-gaming contexts" ([39], p. 1). Typical gamification mechanics and elements are competition, cooperation, assignments, quests, goals, points, levels, badges, and leaderboards [40].

Persuasive apps within the electricity and water domains are fed by consumption data provided by fixed metering infrastructures. Automatic monitoring of individual mobility patterns, instead, requires a new, dedicated, and flexible tracking system, able to follow individuals along their movements. In the last decade, pilot projects aimed at automatic mobility data tracking through smartphone apps, GPS devices and sensors embedded in smartphones were developed [41-48], and, thanks to the fast progress in the quality of automatic mobility tracking, since then several persuasive apps promoting mobility behaviour change have emerged [49-54].

\subsection{Recommendations for Effective Persuasive Apps}

Persuasive apps can be classified under the concept of Behaviour Change Support Systems (BCSS), introduced by Oinas-Kukkonen ([55], p. 1225) to refer to "information systems designed to form, alter or reinforce attitudes, behaviours or an act of complying without using deception, coercion or inducements". Even though persuasive, gamified app-based BCSSs are frequently popping up, their development is still a young endeavour. At a general level, Froehlich and Anagnostopoulou et al. [56,57] identified a number of recommendations for persuasive, gamified systems, which can be summarised as follows:

- Provide information: Information should refer to available transport alternatives tailored to the individual's needs, interests or living context. It should be specifically related to the individual's behaviour and be as timely as possible (close to the triggering cause, in both space and time), thus being easier to understand and remember.

- Provide goal setting opportunities: Allowing individuals to select their own goals and targets for change can have powerful effects, since, when selected targets are really challenging for the individual, they create a self-competitive context leading the individual to strive for personal progress and mastery (intrinsic motivation for change [58]).

- Provide feedback: Since individuals require a baseline to assess their performance and progress over time, providing feedback is complementary to and essential for goal setting activities.

- Provide rewards (incentives) or punishment (disincentives): These can be either tangible or intangible, expressed in monetary terms or in physical units, and need to be strictly related to the individual's performance. Rewards of good performances can reinforce individual motivation to adopt a certain behaviour, while punishment of poor performances can stimulate strengthening individual efforts. Punishment has however to be handled carefully, since it might quickly demotivate [32].

- Provide occasions for social comparison: Offer individuals the opportunity to compare their choices and performances against other people or groups they perceive as similar to themselves, such as members of the same community. This generates both peer pressure and a desire for imitation.

Detailed practical suggestions are also provided by the framework for persuasive systems design (PSD) [59] and further practical guidance is offered by the comprehensive, theory-linked taxonomy of twenty-six behaviour change techniques developed by Abraham and Michie [60] to favour effectiveness, standardisation and replicability of behaviour change interventions. 


\subsection{Limitations of Current Persuasive Apps}

Reviews of key characteristics and limitations of current persuasive apps have already been performed, also with specific reference to apps in the mobility sector [57,61-63], and several aspects were identified to critically affect their overall behaviour change impact.

Above all, similar to voluntary travel behaviour change interventions and soft mobility policies in general, persuasive apps were frequently seen to lack grounds in a proper behaviour change theory, which is supposed to reduce their practical behaviour change effectiveness $[62,64,65]$. The same scholars cast doubts on the claims of effectiveness by their proponents, since they found that most assessments of such app-based interventions were lacking scientific rigour, due to limited adoption of experimental design (randomised controlled trials), the "gold standard" for interventions.

Further, common approaches to the provision of feedback, rewards and goals were questioned. Most of the existing persuasive apps in the mobility field, in fact, rely on a point system, usually allowing for points to be redeemed for real-life goods and services. Points are attributed whenever the detected mobility choices of a user are coherent with a given set of rules, generally in proportion to the number of kilometres travelled with soft transport modes (walking and cycling) and/or public transport. This implies that going for a bicycle ride during leisure time, while continuing to use the car for work commutes, would reward users with points: as remarked by Froehlich [56], such point systems might encourage people to take more trips simply to earn more points, paradoxically ending up worsening their mobility impact, instead of improving it. In addition, other scholars remarked that using the same point-attribution rules for all users fails to acknowledge that there is no "one-size-fits-all" solution $[66,67]$ and that the persuasive effectiveness of a given tool is strictly dependent on individual baselines, viable alternatives, daily needs and constraints, besides individual attitudes and perceptions. Finally, the dominant point-based approach was criticised for its inherent technology patronising and elitist vision [67-69], i.e., designers of persuasive systems apparently know what is always good and right, while ordinary people do not.

Against this background, it was recommended to rethink the currently dominant point-based rewards system, with the aim of giving app users as much freedom and customisation as possible $[56,67]$. For instance, users should be allowed to freely choose their own goal and target for change, by independently deciding if and how much they would like to change. Then, feedback and rewards should explicitly be connected to progress regarding the target they autonomously set for themselves.

\subsection{Research Objectives and Contents of the Paper}

While the above limitations currently affecting persuasive apps have already been identified, how to effectively overcome them is still an open research question. Moreover, additional research should be performed with the aim of directly exploring the perspective of app users to identify further limitations and shortcomings, as well as recommendations for improvement that could inform future development of persuasive apps.

We took on these research challenges within the Swiss-based GoEco! project, aimed at developing a smartphone app that persuades users to reduce their car use and transition to low carbon and energy efficient transport modes (walking, cycling and public transport). Following the above literature, in GoEco! our specific research objective was twofold:

- designing the GoEco! persuasive app so as to overcome the above identified limitations, particularly the lack of grounding in a behaviour change theory and the over-reliance on "one-size-fits-all" point-based reward systems; and

- testing it in real-life settings and identifying additional shortcomings and recommendations for future works, from the perspective of its direct users.

In this paper, we present the methodology we followed to achieve these objectives (Section 2) and the results we obtained, in terms of the GoEco! persuasive app contents and features (Section 3). 
Then, we discuss the evaluation of the GoEco! app effectiveness according to real-life, volunteer users, who experimented it in a three-month field test run in two Swiss regions (Section 4). We conclude by summarising key suggestions and recommendations for future apps aimed at persuading more sustainable mobility patterns in similar, wealthy countries, and commenting on remaining open research challenges (Section 5).

\section{Methodology}

The methodology we followed to achieve the above research objectives is sketched in Figure 1: first, we designed the app's persuasive contents and features (Phase 1), then we field tested it in a three-month real-life intervention (randomised controlled trial, Phase 2), and, finally, we evaluated its contents and features (Phase 3). Throughout these stages, we always adopted a user-centred perspective.

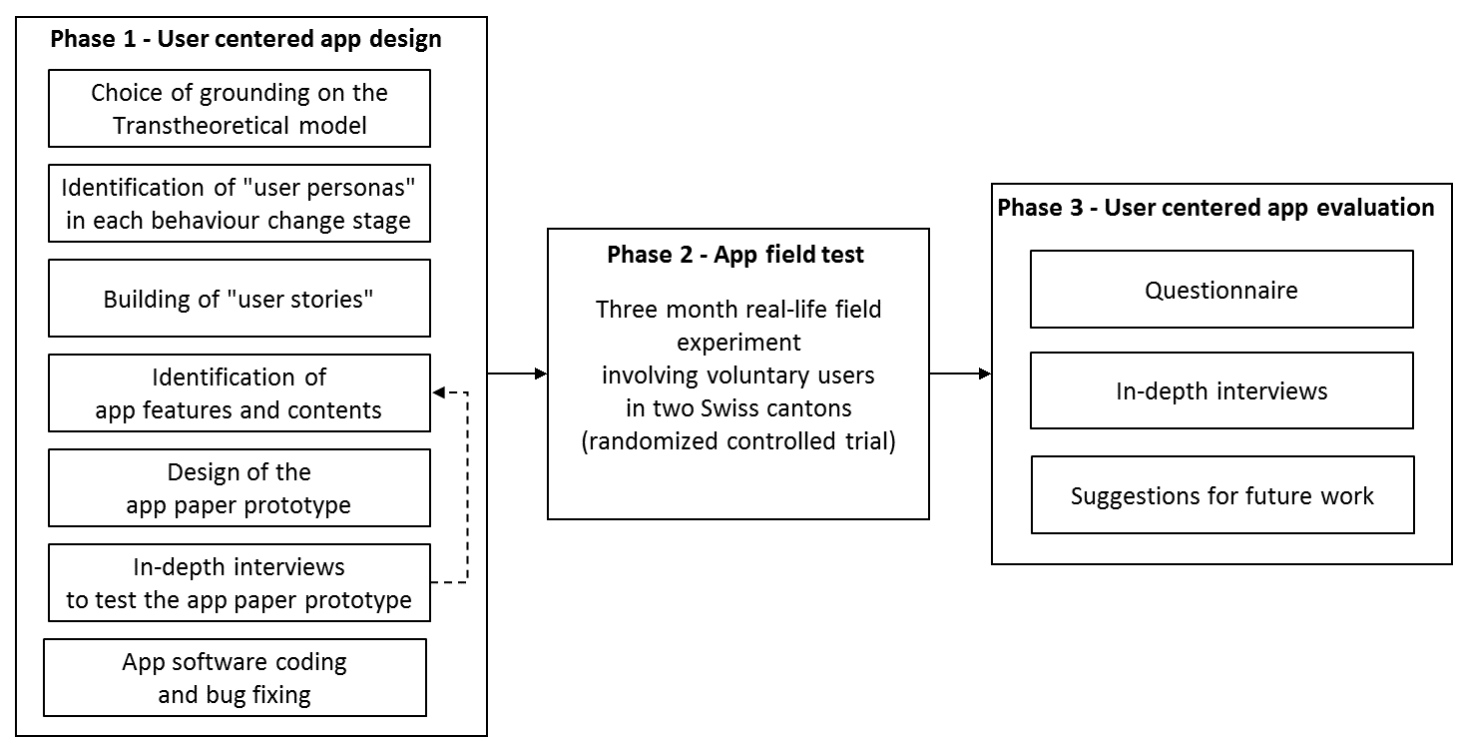

Figure 1. The methodology followed to design and evaluate the GoEco! app.

\subsection{User Centered Design}

As a first step, we selected a relevant behaviour change theory, to which we could anchor the app's features and components. Our understanding of behaviour change processes was framed in the transtheoretical model [70]: individual behaviour change does not happen as a single event, instead it occurs through a number of processes that lead the individual to progress along a set of cognitive and motivational stages, from pre-contemplation to maintenance of change. Therefore, persuading an individual to change her behaviour actually requires different processes, depending on the specific stage she is in-and a persuasive app such as GoEco! should be capable of providing each user with the most appropriate set of features and components to facilitate the activation of each specific process. To design such app features and components, we opted for a user centred design approach [71,72]. Following the authors of [73-75], we developed a "user persona" profile for each stage of the behaviour change process towards the reduction of car use. Such personas were fictitious user characters, designed by explicitly referring to individuals we had observed and interacted with during a previous app-based mobility tracking intervention run in the Italian-speaking part of Switzerland [76]. We then developed "persona stories" [77], namely descriptions of when the above personas would interact with the GoEco! app, why, and how. In developing such stories, we referred to the motivational techniques suggested by Prochaska and Velicer [70] for each behaviour change stage, by the framework for persuasive systems design [59] (as later revised by Sunio and Schmöcker [62]) and by the taxonomy for behaviour change interventions [60]. In parallel, we also designed the app user interface elements. 
As soon as a sufficiently accurate app paper prototype was available, it was tested through in-depth interviews with four possible app users, each of whom was in a different stage of the behaviour change process. Interviewees were voluntary-recruited colleagues, not engaged in our specific research field to reduce self-selection bias, and attributed to a specific behaviour change stage according to a screening question by Bamberg [78] (people in the action and maintenance stages were considered equivalent, since they are affected by similar processes for change).

\subsection{Field Test}

Based on feedback from these interviews, the app's components and features were reworked and updated, and then the paper prototype was turned into a software prototype, on which testing and bug fixing activities were performed. The resulting GoEco! app was subsequently field-tested in a three-month randomised controlled trial, run between October 2016 and January 2017 in two Swiss cantons (Ticino and Zurich, in the Italian- and German-speaking parts of Switzerland, respectively) [79]. The experiment involved 212 self-selected individuals, who voluntarily answered a public call to participate in the GoEco! field test. Two thirds of them (145 individuals, 69 in Ticino and 76 in Zurich) were invited to test the GoEco! app (treatment group), while one third of them (67 individuals, 34 in Ticino and 33 in Zurich) was only passively tracked to gather counterfactual mobility data (control group). The call was spread through a press-conference with local communication media (radio, television and newspapers), paid and regular communications on social media channels, and an in-person event directly targeting interested citizens. Throughout the trial, a number of drop-outs occurred, so that the number of active testers of the GoEco! app decreased from 145 to 47 (27 in Ticino and 20 in Zurich). Such self-selection recruitment processes are typically affected by a volunteer selection bias $[80,81]$, which in turn might affect the possibility to generalise the project results. It is in fact well-known that opt-in frameworks such as the one adopted in GoEco! tend to raise the interest of already motivated subgroups of the general population, thus tending to engage individuals with higher than average environmental awareness and pro-environmental attitude. Nonetheless, in interventions such as GoEco!, which require active and conscious engagement with a smartphone app, no obligations can be put into force and no opt-out strategies can be implemented. Therefore, a self-selection of participants can barely be avoided and a related bias has to be taken into account. Similar tendencies might also have occurred throughout the app field test, with higher drop-out rates by individuals with lower environmental awareness and attitude. A questionnaire targeting all initial project participants attributed to the treatment group (145 individuals) showed that the two major reasons for leaving the project were related to the need for confirmation of the mobility data automatically tracked (validation, see Section 3.1) and technical problems precluding, from time to time, the app from fully working.

\subsection{User-Centred Evaluation}

The evaluation of the experiment from the participants' perspective was performed by a mixed quali-quantitative survey, consisting of an online questionnaire and individual interviews.

Six months after the trial (between June and July 2017), a questionnaire was administered to the project participants to explore how they evaluated the app's persuasive features and components. The questionnaire was created with the Google Forms platform and its link was sent to all project participants via email. No obligations to answer were set, instead incentives were made available, through a final draw among respondents, offering 20 prizes of the value of 50 Swiss francs each (vouchers for Swiss retailers, public transport tickets, or charity donations). The questionnaire consisted of nine parts, for an estimated 15 minutes answering time and a total of 32 multiple-choice questions, 11 of which were mandatory to complete the questionnaire. Overall, 45 users responded to the questionnaire (though only 21 of them answered all questions, including non-mandatory ones), and the collected data were analysed through descriptive statistics techniques, via the IBM SPSS software package. 
Moreover, ten months after the end of the field experiment (December 2017), 20 respondents of the questionnaire were randomly selected for an additional in-person, semi-structured interview, aimed at in-depth discussion and collection of bottom-up recommendations for future similar persuasive apps. Users accepting to join the interview were rewarded with a 50 Swiss francs voucher, and in the end 19 interviews were performed (11 in Ticino and 8 in Zurich). The interviews were held in the official language of each canton (Italian in Ticino and German in Zurich). They were recorded and detailed reports were produced in their original language, while no full transcription of the recorded material was performed. The reports were then analysed in a "grounded theory inspired approach" [82,83].

To avoid biases, two researchers independently analysed the reports and coded categories in English, following the constant comparative method suggested by [84]: when semantically similar category labels were identified, they were compared and discussed, and the most appropriate one was selected. Once the list of categories was definitively established (in English), the interview reports were read again and every occurrence of a category was registered in a matrix, together with a quotation of the direct words of the participants, if they were especially clarifying. These quotations were first recorded in the original language and then translated into English, with the aim of keeping the original meaning of the words of the interviewee as much as possible.

Finally, a cross-analysis of the elements emerging from questionnaire and interviews was performed, which allowed us to reciprocally enrich and sustain the insights they individually provided.

A quantitative assessment of the effectiveness of the GoEco! app in producing tangible behaviour change in terms of individual mobility patterns and the related impact on energy consumption and $\mathrm{CO}_{2}$ emissions was performed as well, through analysis of the mobility data directly tracked by the app in the GoEco! randomised controlled trial (comparison before/after the intervention, with respect to a similar control group).

\section{Results: An App Supporting Behaviour Change Step by Step}

In this section, we summarise the results of the app design activities performed in Phase 1 , by presenting the GoEco! app's components and features. Since they were developed with the aim of fostering progress from a specific stage of the behaviour change process to the next one, we introduce them from the perspective of each behaviour change stage: pre-contemplation (of change), contemplation, preparation, action, maintenance, and termination. To facilitate comparison with other (app-based) BCSSs, we also refer to the framework for persuasive systems design [59] and the taxonomy for behaviour change interventions [60]: Table 1 shows an overview of all GoEco! features and components, allowing to frame them in terms of both the theoretical background and the persuasive principles and techniques they exploit.

Table 1. Features and components of the GoEco! app, with respect to the stages and processes of change identified by the transtheoretical model [70], the techniques for behaviour change interventions by Abraham and Michie [60], and the framework for persuasive systems design [59,62].

\begin{tabular}{lllll}
\hline Stage of Change & Processes of Change & $\begin{array}{l}\text { GoEco! } \\
\text { Components/ } \\
\text { Features }\end{array}$ & $\begin{array}{l}\text { Techniques for } \\
\text { Behaviour Change } \\
\text { Interventions }\end{array}$ & $\begin{array}{l}\text { Framework for } \\
\text { Persuasive Systems } \\
\text { Design }\end{array}$ \\
\hline & $\begin{array}{l}\text { Consciousness raising } \\
\text { Increase awareness for } \\
\text { causes, consequences } \\
\text { and cues about a } \\
\text { behaviour }\end{array}$ & $\begin{array}{l}\text { Feedback on each } \\
\text { travelled route and } \\
\text { Baseline mobility } \\
\text { patterns }\end{array}$ & $\begin{array}{l}\text { 1. Provide general } \\
\text { information } \\
\text { 2. Provide information } \\
\text { on consequences } \\
\text { 13. Provide feedback on } \\
\text { performance }\end{array}$ & $\begin{array}{l}\text { Self-monitoring } \\
\text { Tailoring } \\
\text { Reduction }\end{array}$ \\
\hline & $\begin{array}{l}\text { Self-reevaluation } \\
\text { Cognitive and affective } \\
\text { assessment of one's } \\
\text { self-image, with and } \\
\text { without a particularly } \\
\text { unhealthy habit }\end{array}$ & $\begin{array}{l}\text { Alternatives for } \\
\text { systematic routes } \\
\text { and overall } \\
\text { potentials for } \\
\text { change }\end{array}$ & $\begin{array}{l}\text { 8. Provide instructions } \\
\text { 9. Model or demonstrate } \\
\text { the behaviour }\end{array}$ & $\begin{array}{l}\text { Simulation } \\
\text { Tailoring }\end{array}$ \\
& & & & \\
\hline
\end{tabular}


Table 1. Cont.

\begin{tabular}{|c|c|c|c|c|}
\hline Stage of Change & Processes of Change & $\begin{array}{l}\text { GoEco! } \\
\text { Components/ } \\
\text { Features }\end{array}$ & $\begin{array}{l}\text { Techniques for } \\
\text { Behaviour Change } \\
\text { Interventions }\end{array}$ & $\begin{array}{l}\text { Framework for } \\
\text { Persuasive Systems } \\
\text { Design } \\
\end{array}$ \\
\hline Preparation & $\begin{array}{l}\text { Self-liberation } \\
\text { The belief that one can } \\
\text { change and commitment } \\
\text { to act on such a belief }\end{array}$ & Goal setting & $\begin{array}{l}\text { 4. Prompt intention } \\
\text { formation } \\
\text { 10. Prompt specific goal } \\
\text { setting }\end{array}$ & $\begin{array}{l}\text { Reduction } \\
\text { Personalisation }\end{array}$ \\
\hline \multirow{6}{*}{ Action and Maintenance } & \multirow[t]{2}{*}{$\begin{array}{l}\text { Counterconditioning } \\
\text { Learning of more } \\
\text { sustainable behaviours } \\
\text { that can substitute the } \\
\text { less sustainable ones }\end{array}$} & Challenges & $\begin{array}{l}\text { 7. Set graded tasks } \\
\text { 8. Provide instructions }\end{array}$ & $\begin{array}{l}\text { Suggestion } \\
\text { Reduction } \\
\text { Rehearsal } \\
\text { Tunnelling }\end{array}$ \\
\hline & & $\begin{array}{l}\text { Weekly report of } \\
\text { individual progress }\end{array}$ & $\begin{array}{l}\text { 12. Prompt } \\
\text { self-monitoring of } \\
\text { behaviour } \\
\text { 13. Provide feedback on } \\
\text { performance }\end{array}$ & Self-monitoring \\
\hline & \multirow[t]{2}{*}{$\begin{array}{l}\text { Contingency management } \\
\text { Provide consequences } \\
\text { (rewards) for taking } \\
\text { steps in a particular } \\
\text { direction }\end{array}$} & Trophies and Badges & $\begin{array}{l}\text { 13. Provide contingent } \\
\text { rewards }\end{array}$ & $\begin{array}{l}\text { Praise } \\
\text { Rewards }\end{array}$ \\
\hline & & $\begin{array}{l}\text { Leaderboard/ } \\
\text { Hall of Fame }\end{array}$ & $\begin{array}{l}\text { 19. Provide } \\
\text { opportunities for social } \\
\text { comparison }\end{array}$ & $\begin{array}{l}\text { Social comparison } \\
\text { Recognition } \\
\text { Competition } \\
\text { Similarity }\end{array}$ \\
\hline & \multirow[t]{2}{*}{$\begin{array}{l}\text { Helping relationship } \\
\text { Social support (care, } \\
\text { trust, openness, } \\
\text { acceptance and general } \\
\text { support) for new } \\
\text { behaviour }\end{array}$} & $\begin{array}{l}\text { Notification system } \\
\text { to stimulate action } \\
\text { maintenance }\end{array}$ & $\begin{array}{l}\text { 6. Provide general } \\
\text { encouragement } \\
\text { 17. Prompt practice }\end{array}$ & Reminder \\
\hline & & $\begin{array}{l}\text { In-person events } \\
\text { outside the app }\end{array}$ & $\begin{array}{l}\text { 6. Provide general } \\
\text { encouragement }\end{array}$ & $\begin{array}{l}\text { Social learning } \\
\text { Social facilitation } \\
\text { Reminder }\end{array}$ \\
\hline
\end{tabular}

\subsection{Pre-Contemplation Stage—Getting Feedback on Individual Baselines}

App users in the pre-contemplation stage have no motivation for reducing car use and do not intend to take action to change their daily mobility patterns. This might be due to insufficient information about their possibilities for change or to a lack of trust in their ability to change. To support users towards change, at this step, Prochaska and Velicer [70] suggested implementing consciousness raising. In GoEco!, this is performed by increasing users' awareness about consequences and practical mobility options available to them: the app provides users with an automatic feedback on each route they travel, in terms of distance, time, energy consumption, and $\mathrm{CO}_{2}$ emissions (self-monitoring).

To provide such feedback, GoEco! tracks individuals' mobility data. For this purpose, it exploits the Application Programming Interface (API) of the commercial, free fitness tracker app Moves [85] (discontinued since July 2018), that records users' positions, segments travelled paths into "routes" and "activities", and automatically determines whether they are walking, running, cycling, or taking another mode of "transport". Building on this information, new algorithms developed specifically for GoEco! further classify the generic "transport" activities identified by Moves, so that also bus, train and tram mode activities are automatically detected. To produce the needed fine-grained distinction between these different transport modes, a classifier based on a naïve Bayes algorithm [86] was built, which takes into account several route characteristics, such as travel speed, acceleration, or spatiotemporal dependencies between visited points and the public transport network (stops and lines). The whole algorithm is presented in detail in [87]. As Moves data are updated at unknown points in time, GoEco! is not capable of providing real-time feedback. Instead, users are encouraged to interact with it once a day, with the purpose of checking and validating the automatically detected 
transport mode for every activity tracked on the previous day (Figure 2a,b). While performing this validation, they receive the feedback on both transport-related indicators and related impacts.

The impacts are expressed in terms of primary energy consumption $(\mathrm{kWh})$ and $\mathrm{CO}_{2}$ equivalent emissions and are based on the Mobitool consumption and emission factors [88], which depend on the mode of transport, refer to a single kilometre travelled in Switzerland and take into account the consumption and emissions of the full life-cycle, by considering an average vehicle occupancy. The specific values are presented in [87]. For electricity-fuelled transport modes, such as trains, these factors heavily depend on the involved power generation systems (e.g., power from renewable sources leads to much fewer $\mathrm{CO}_{2}$ emissions than power generated by fossil-fuel power plants). As such, these factors and the resulting energy consumption and $\mathrm{CO}_{2}$ emission values are specific to Switzerland. To apply the framework to other countries, their power generation systems have to be analysed and taken into account accordingly.

Regarding cars, the Mobitool values reflect the powertrain composition of the Swiss vehicle fleet of passenger cars. To get more meaningful feedback, GoEco! app users can enter the average fuel consumption of their car (expressed in fuel litres per $100 \mathrm{~km}$ ), otherwise GoEco! automatically considers the Mobitool default values. Electric cars are not automatically identified by the system, since GoEco! has no elements to distinguish them from internal combustion engine cars; however, whenever anyone uses an electric car, they can manually select it when validating the transport mode, therefore GoEco! can account for the related energy consumption and $\mathrm{CO}_{2}$ emission factors.

Equally, the systems is not capable of automatically detecting the number of users travelling in the same car, therefore ridesharing or car-pooling routes cannot be accounted for by the app. Acknowledging these limitations, therefore, the feedback on one's own mobility impact is meant as a reference, for comparison with the other transport modes.
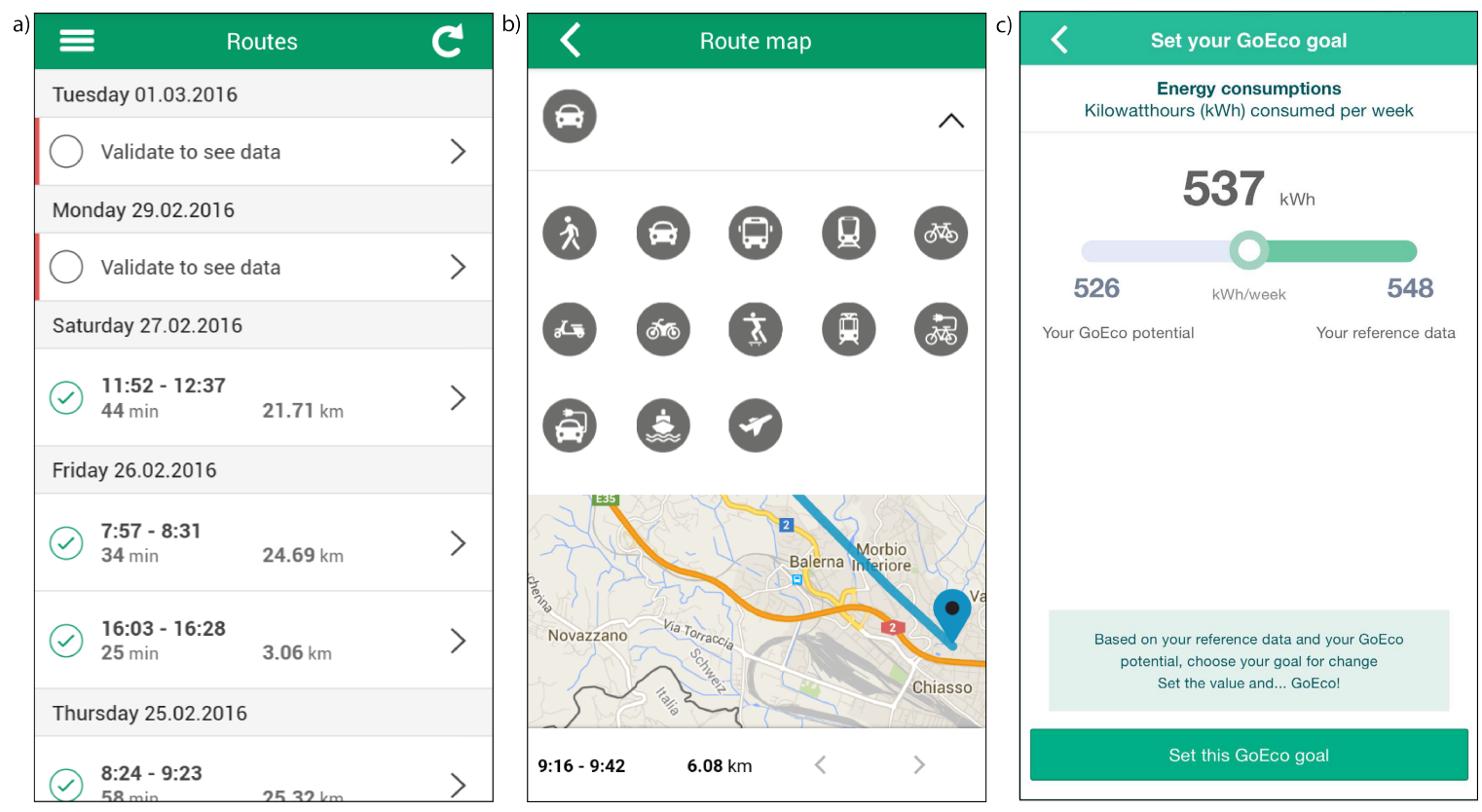

Figure 2. A selection of screens of the GoEco! app: (a) list of tracked activities; (b) manual validation of the transport mode; and (c) goal setting.

After four weeks of use of the GoEco! app, namely when a sufficient amount of diverse mobility data are gathered, GoEco! provides users with a summary of their personal "baseline mobility patterns". These baselines are expressed on a weekly basis and summarise the average kilometres travelled, the time spent travelling, and the use of each transport mode in percent (aggregated into the following categories: car, public transport, bicycle, walking, other). A richer and more detailed individual 
report is also made available outside the app and sent via email as a PDF document (see Figure 3a). By offering the users a glimpse of their mobility patterns as a whole, the feedback on such baselines allows reducing the complexity of processing each single route (reduction).

\subsection{Contemplation Stage-Receiving Information on Individual Potentials For Change}

The above feedback is expected to increase users' awareness about pros and cons of changing their behaviour, thus leading them to develop the intention to change in the near future. When this happens, they enter the contemplation stage. To avoid users remaining at this stage, stuck in "chronic contemplation" of elements in favour and against a change in their behaviour, GoEco! stimulates them with an additional feedback on the available low-carbon alternatives for any systematic route they travel and on their overall "potential for change" - a summary of how they could move, by always choosing the available alternative route with the lowest $\mathrm{CO}_{2}$ emissions (simulation, tailoring).

Leading users to perform a cognitive assessment of their self image, under both their "baseline" car-dependent mobility patterns and their "potential" mobility patterns (that are more sustainable), this feedback is expected to stimulate a self-reevaluation process, which, according to the transtheoretical model, would in turn prompt progress to the preparation stage.

To estimate the "potential" mobility patterns, GoEco! processes the four-week data already used to determine the "baseline" mobility patterns through additional algorithms that assess the feasibility of replacing the transport mode of any travelled route with low carbon ones [87]. The resulting "potential mobility patterns" are summarised in the GoEco! app and also in an external PDF report sent via email (see Figure $3 b$ ), which also provides specific information about viable, $\mathrm{CO}_{2}$ efficient alternatives for every automatically identified "systematic loop", namely for every home-to-home frequently travelled route.

a) Your baseline mobility patterns

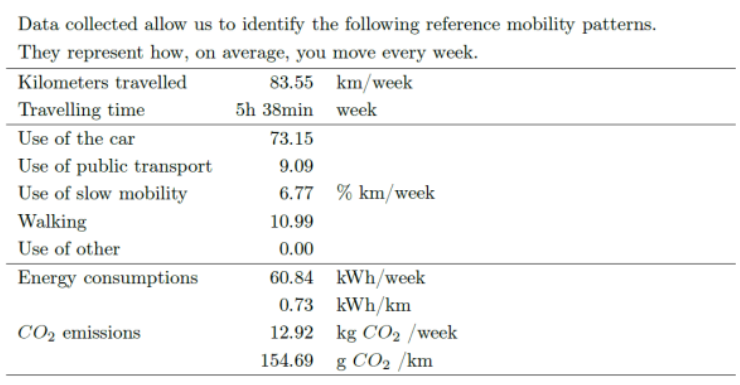

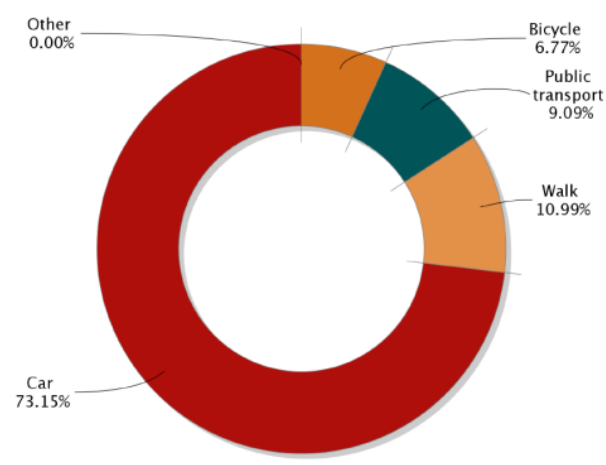

b) Your potential mobility patterns

\begin{tabular}{lrl}
$\begin{array}{l}\text { If you could use the most energy-efficient alternatives available for all your journeys, } \\
\text { you could have the following mobility patterns. }\end{array}$ \\
\hline Kilometers travelled & 65.21 & $\mathrm{~km} /$ week \\
Travelling time & $5 \mathrm{~h} 18 \mathrm{~min}$ & /week \\
\hline Use of the car & 52.82 & \\
Use of public transport & 24.91 & \\
Use of slow mobility & 7.88 & $\% \mathrm{~km} /$ week \\
Walking & 14.40 & \\
Use of other & 0.00 & \\
\hline Energy consumptions & 37.51 & $\mathrm{kWh} /$ week \\
& 0.58 & $\mathrm{kWh} / \mathrm{km}$ \\
$\mathrm{CO}_{2}$ emissions & 7.56 & $\mathrm{~kg} \mathrm{CO} /$ week \\
& 115.97 & $\mathrm{~g} \mathrm{CO} 2 / \mathrm{km}$ \\
& &
\end{tabular}

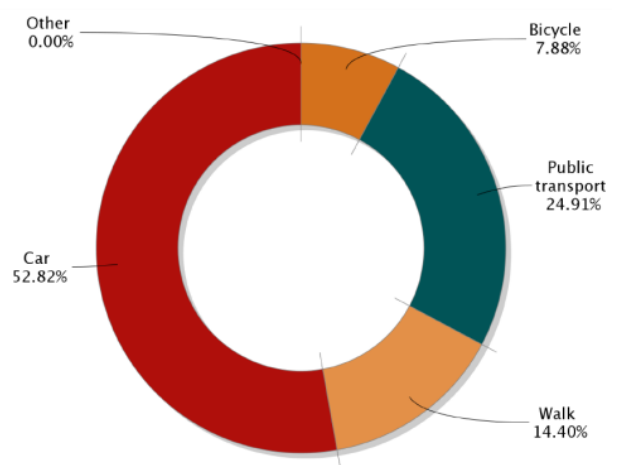

Figure 3. A user's baseline (a) and potential (b) mobility patterns, as provided in the PDF reports sent via email. 


\subsection{Preparation Stage_-Setting Individual Goals For Change}

Preparation is the crucial stage during which individuals develop plans for action, with the intention of putting them into practice in the near future. To enhance self-liberation (the belief that one can change and the commitment to act on such a belief), GoEco! stimulates app users to set their own goals for change. Users are offered a choice among five goals, that are closely related to each other and explicitly address the concept of change with respect to the GoEco! baseline mobility patterns: Reduce car use, Increase slow mobility, Increase public transport (in percentages of the weekly kilometres travelled), Reduce energy consumption, and Reduce $\mathrm{CO}_{2}$ emissions.

Once they have chosen their favourite goal, users are invited to set the related target, by selecting a value between their baseline mobility patterns and their potential for change through a slider component, as shown in Figure 2c. The choice of such a target indicates the amount of change they would like to achieve and is therefore related to the amount of effort they plan to invest in trying to reduce their car-dependency. This choice is on purpose fully left to the users (personalisation), to avoid any one-size-fits-all, patronising or super-imposed solution. In fact, not only depending on the places where they live and work, individuals have different access to car alternatives, but also, depending on their family needs, may have different mobility requirements, which affect the practical feasibility of the potential for change estimated by GoEco!: in some cases even small targets for change might imply a significant reorganisation of one's individual and family routines and habits.

Finally, both the goal and the target value can be changed over time, thus allowing users to start with relatively easy targets and to later increase difficulty (reduction), or to simplify their target, in case they started with one that was too challenging. Users are therefore free to progress at their own pace and in their own direction, while being stimulated by GoEco! to achieve their personal goal for change.

\subsection{Action and Maintenance Stages_Practicing New Behaviours and Being Individually and Socially Rewarded}

Having committed themselves to their own goal, to enter the action stage, users need practical support and suggestions on how to perform the change (counter-conditioning, namely learning more sustainable behaviour with respect to their current one). Then, they need to be rewarded for the efforts they have performed in trying to put the new behaviour into practice (contingency management) and to be shown that the new behaviour enjoys a favourable opinion at the social level (helping relationship and social support).

As long as individuals practice with the implementation of the new behaviour, they enter the maintenance stage, during which the need for external support decreases, they are less tempted by relapse and more confident that they can maintain their change. To avoid relapse, which is always possible and would lead individuals back to an earlier stage (in the worst case to pre-contemplation), the same techniques as in the action stage can be put into practice-however, they will be needed less frequently. The behaviour change process concludes when individuals reach the termination stage, namely they have no temptation and the new behaviour is regularly put into practice. In such a condition, the GoEco! app would no longer be needed and users could confidently stop using it, having managed to improve their mobility patterns.

\subsubsection{Practicing New Behaviours and Getting Individual Rewards}

To help individuals to achieve their goal step-by-step (reduction), GoEco! offers them to join individual challenges that prompt them to put specific, more sustainable mobility choices into practice, such as I will not use the car during peak hours for three days out of the next seven days, I will not use either cars or planes for the whole weekend or this week I will travel all my short routes by slow mobility (Figure 4a). By providing practical suggestions, challenges are particularly helpful in supporting individuals to concretely step out of their mobility habits. These hands-on challenges help "unfreezing" specific mobility choices that individuals were performing without any premeditation or deliberative reasoning (automatic mental processes) while in the pre-contemplation stage, turning them into controlled mental 
processes, moved instead by intention, cognitive effort and awareness [89]. Users are free to join the challenge(s) they prefer or ignore them. If they join one, GoEco! automatically assesses their performances, rewarding them with a bronze trophy if they achieve it. Successfully repeating the same challenge over time allows levelling up (rehearsal): the duration of the challenge increases from one week to longer periods and its achievement is rewarded with higher-level trophies (silver, gold and platinum). Another way to level up is to get engaged in similar, but more difficult, challenges. For example, after achieving the Three days without car in peak hours challenge, they could engage in the Five days without car in peak hours challenge (tunnelling). Repetition is essential, since it helps users to stay with their new mobility patterns and make them habitual.

GoEco! also provides users with surprise rewards (badges) if it detects they have spontaneously performed sustainable mobility choices, such as "using the bicycle every day for at least five consecutive days" or "travelling long trips by train". Receiving an unexpected reward for such spontaneous actions makes users aware of the good choices they have performed without any deliberate reasoning (activation of a cognitive dissonance between their usual behaviour and their attitude [90]), thus stimulating them to repeat the action in the future. Moreover, since they are unexpected, badges rekindle users' commitment to implement their action plan towards achievement of their goal. Note that GoEco! trophies and badges are only virtual and no points to be redeemed for real-life prizes are available. This is because the overarching aim of GoEco! is to stimulate mobility behaviour change as a personal, intrinsic choice of app users, instead of buying it in exchange for money or other tangible goods, which has been found to only have temporary effects [91].

Overall, in the action stage individuals need to consciously act to change their daily patterns. To further support conscious action, GoEco! also provides users with a weekly notification praising them about progress towards their own goal (self-monitoring), which is visualised by a simplified bar chart, where the height of the bar is proportional to the percentage of the goal having been achieved in the past seven days (see Figure 4 b). Further notification elements are daily reminders to check and validate the tracked routes, a weekly notification on the update of individual and collective comparison statistics, congratulation messages whenever users achieve good results (goal achievement, challenge conclusion, attribution of badges, visibility in the Hall of Fame), and encouragement messages to try again in the following weeks in case of failure of challenges or goals.

\subsubsection{Getting Social Reward and Support}

A notification system congratulating for achieved results can substitute for an in-person counsellor, enhancing the perception of social support. However, virtual communities might be less effective in motivating to change, especially in the long term, if no direct and in-person interactions among the users are possible. To anticipate a critical decrease of interest of users and to prevent them from stopping to use the app before they permanently change their mobility patterns, in the action and maintenance stages, virtual activities are backed up with in-person events outside the app, open to the whole GoEco! community and their circle of family and friends. On a monthly basis, in fact, users are invited to join recreational events related to sustainable mobility topics, such as visits to exhibitions, slow mobility and public transport treasure hunts across the city or lazy bicycle rides in natural areas. During such events, the app users get to know each other, share their experiences and tips to overcome difficulties in achieving challenges and, in general, support and motivate each other towards their personal goals for change (social learning and facilitation).

To reinforce the users' motivation to adopt a different behaviour, GoEco! also builds on individual competitive attitudes, offering weekly comparisons with peer members of the same community (social comparison, competition), which is usually assessed as a powerful approach to increase motivation for change [92]. Typically, in gamified contexts this is performed by ranking users in a leaderboard, based on the number of points they earned. However, to overcome the limitations about points introduced in Section 1.3, and especially due to the difficulty of ensuring a fair distribution of points, if one wants to respect all heterogeneous individual circumstances and stay transparent, in GoEco!, we explicitly 
opted for avoiding a point-based reward system, putting instead goals at the centre of the process of change. Thus, comparison between members of the GoEco! community is based on the level of achievement of one's own goal, combined with the number of completed challenges (trophies) and the number of obtained badges. On a weekly basis, these indicators are computed, the GoEco! leaderboard is also updated, and the top-3 users of the week are posted in the "Hall of Fame section" (recognition) (Figure 4c). To provide users with comparisons, which are valuable and meaningful, comparison in the leaderboard can also be made against a subset of users who are pursuing the same type of goal for change or whose homes have the same level of accessibility to public transport, based on a classification available for all Switzerland [93] (similarity).

Such a configuration implies that, regardless of the specific effort each user needs to devote to achieve her goal for change, every week any user could be shown in the "Hall of fame", depending on how close she gets to her target and on how many trophies and badges she collected. The system does not judge the level of difficulty associated with the goal and target chosen by the user, or the level of difficulty of the obtained trophies (which depend on the user's initial mobility patterns, on her potential for change, on external, personal constraints, and on her level of engagement with the app), and assumes that all users have genuinely set the most proper goals and targets for themselves.
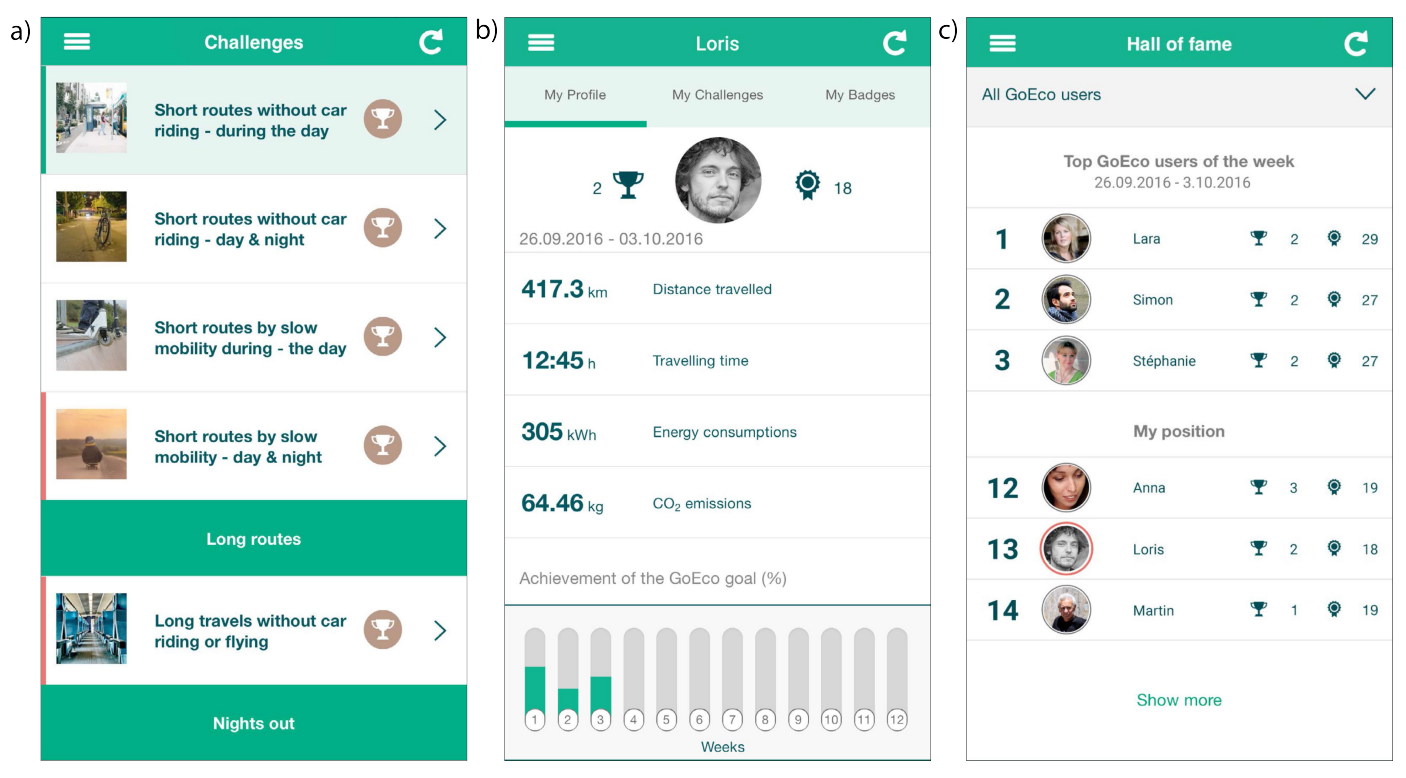

Figure 4. A selection of screens of the GoEco! app: (a) list of available challenges; (b) weekly summary feedback on individual performances; and (c) Hall of Fame (top users in the weekly leaderboard).

\section{Discussion: User Evaluation of GoEco! App's Persuasive Features and Components}

The GoEco! app was designed with the explicit aim of overcoming the limitations already identified in the literature. However, how did users evaluate its components and features and which suggestions would they provide for future similar apps? To answer this question, we collected material from a three-month field experiment that involved the 47 active testers in the two Swiss regions of Zurich and Ticino, through a survey composed of an online questionnaire and individual interviews.

Answering the questionnaire was not mandatory for all questions, therefore the sample of respondents varies from a minimum of 21 to a maximum of 45 users, depending on the question. Basic socio-economic characteristics of questionnaire respondents and interviewees are shown in Table 2: medium to high income individuals, mostly males, with a balanced age distribution between 25 and 54 years old. According to their answers to the questionnaire, reported in Table 3, they have a medium to high pro-environmental attitude, and also share the feeling of a personal responsibility to control pollution and climate change. Since no direct comparison is possible with corresponding figures for the average population, we cannot state whether these figures indicate the presence of 
a self-selection bias. However, even in the case it occurs, this does not disallow investigating the user's opinions and viewpoints with respect to the app's features and contents. In the following, when appropriate, we directly report elements collected during the interviews, by stating the numerical identification code attributed to the given interviewee (where $\mathrm{T}$ stands for Ticino and $\mathrm{Z}$ for Zurich).

Table 2. Socio-economic characteristics of questionnaire respondents and interviewees. Since answering was not mandatory for all questions, some respondents only partially answered the questionnaire.

\begin{tabular}{|c|c|c|c|c|}
\hline & & $\begin{array}{l}\text { Partial } \\
\text { Questionnaire } \\
\text { Answer } n=45\end{array}$ & $\begin{array}{l}\text { Full } \\
\text { Questionnaire } \\
\text { Answer } n=21\end{array}$ & $\begin{array}{l}\text { Interviews } \\
n=19\end{array}$ \\
\hline \multirow{2}{*}{ Gender } & Female & 17 & 8 & 5 \\
\hline & Male & 28 & 13 & 14 \\
\hline \multirow{5}{*}{$\begin{array}{c}\text { Age } \\
\text { (years old) }\end{array}$} & $20-24$ & 2 & 2 & 1 \\
\hline & $25-34$ & 13 & 8 & 5 \\
\hline & $35-44$ & 13 & 7 & 5 \\
\hline & $45-54$ & 14 & 4 & 6 \\
\hline & $55-64$ & 3 & 0 & 2 \\
\hline \multirow{6}{*}{$\begin{array}{c}\text { Income } \\
\text { (CHF/month) }\end{array}$} & Between 3000 and 4500 & 2 & 0 & 1 \\
\hline & Between 4500 and 6000 & 8 & 4 & 2 \\
\hline & Between 6000 and 9000 & 10 & 6 & 5 \\
\hline & Between 9000 and 12,000 & 8 & 4 & 3 \\
\hline & More than 12,000 & 10 & 3 & 4 \\
\hline & I prefer not to say it & 7 & 4 & 4 \\
\hline \multirow[t]{2}{*}{ Location } & Ticino & 27 & 13 & 11 \\
\hline & Zurich & 18 & 8 & 8 \\
\hline
\end{tabular}

Table 3. Pro-environmental attitude of the questionnaire respondents ( 45 respondents out of 47 active testers). A seven-point Likert score was used, where $1=$ "Totally disagree" and 7 = "Totally agree".

\begin{tabular}{lc}
\hline & M (SD) \\
\hline Climate change is a problem for society & $6.47(0.84)$ \\
Saving energy helps to limit climate change & $6.31(0.90)$ \\
The quality of our environment will improve if we use less energy & $6.16(1.35)$ \\
I feel responsible for pollution and climate change: it is not just a matter of & $5.67(1.22)$ \\
governments and industries & \\
I try to use the car as little as possible & $5.56(1.39)$ \\
\hline
\end{tabular}

To start with, users were asked to assess their overall experience with the app, in terms of its usability, the design of the user interface, the time effort needed to interact with it, and the overall usefulness and pleasure of the experience it delivered. Semantic differential questions were used and the answers were organised on a seven-point Likert scale. As Table 4 shows, above average evaluations were attributed to all the considered evaluation criteria. The least appreciated criterion, however, was the one related to the expenditure of time needed to interact with the app. In fact, during interviews, most users complained about the requested validation of the transport modes: "there was too much manual work, that needed a lot of time" (Z3); "validation was boring, if you did it every day. But if you forgot validating your trips for a week, and then you tried to validate all them at once... it became annoying!"(T11) Therefore, while users acknowledged the importance of validating the transport modes, they also asked for improved automatic detection capabilities (better segmentation of trips and identification of the transport mode): "people should not be forced to validate all their trips" (Z7); "because in some cases trips were-wrongly — highly segmented" (T1); and "at least for walking and car trips, detection of the transport mode should be fully autonomous" (T4). 
Another general comment that emerged from the interviews highlighted an initial barrier to effective use of the app, due to the richness of its features and components: "the app offered quite a lot of features, which were also related to another: you had to fully understand all of them and also the way they were related, which was not always straightforward. To avoid too much burden on the user, you might release new features over time. For example, first you enable goal setting; then, after a few days of app use, you enable challenges as well, and so on" (T11). Namely, users suggested to include an on-boarding phase for each feature, providing the user with enough time to get acquainted with it, before adding more complexity with a new feature.

Table 4. General assessment of the GoEco! app, according to the final questionnaire.

\begin{tabular}{lcccccccccc}
\hline & \multicolumn{1}{c}{ Total $(\boldsymbol{n}=\mathbf{4 5 )}$} & & & M & SD \\
\hline & $\mathbf{1}$ & $\mathbf{2}$ & $\mathbf{3}$ & $\mathbf{4}$ & $\mathbf{5}$ & $\mathbf{6}$ & $\mathbf{7}$ & & 6.20 & 1.01 \\
Difficult to install & 0 & 0 & 1 & 3 & 4 & 15 & 22 & Easy to install & 5.51 & 1.41 \\
Difficult to use & 1 & 0 & 4 & 5 & 6 & 18 & 11 & Easy to use & 4.73 & 1.45 \\
Unattractive in design & 1 & 3 & 5 & 8 & 12 & 13 & 3 & Attractive in design & 4.31 & 1.83 \\
Time-consuming & 4 & 6 & 6 & 4 & 8 & 15 & 2 & Time-efficient & 5.07 & 1.37 \\
Uninformative & 1 & 2 & 1 & 9 & 14 & 12 & 6 & Informative & 5.69 & 1.24 \\
Useless & 1 & 1 & 0 & 2 & 12 & 18 & 11 & Useful & 5.20 & 1.50 \\
Boring & 1 & 2 & 5 & 1 & 14 & 14 & 8 & Interesting & 5.13 & 1.33 \\
Not fulfilling my expectations & 1 & 1 & 3 & 6 & 14 & 15 & 5 & Fulfilling my expectations & 5.13 & \\
\hline
\end{tabular}

For a general screening of the GoEco! features, we then investigated their capability to stimulate app users to adopt more sustainable mobility patterns: as shown in Table 5, those related to the provision of feedback were assessed as the most effective ones, while the possibility to compare individual performances against other users was assessed as the least effective one. In the next sections, we explore these evaluations in more detail, with respect to the key recommendations for effective persuasion, as summarised in Section 1.2.

Table 5. Assessment of GoEco! features, with respect to their effectiveness in stimulating more sustainable mobility patterns. The assessment was based on a seven-point Likert scale, where $1=$ "Not at all effective" and $7=$ "Extremely effective".

\begin{tabular}{|c|c|c|c|c|c|c|c|c|c|}
\hline & \multicolumn{7}{|c|}{ Total $(n=25)$} & \multirow[b]{2}{*}{$\mathbf{M}$} & \multirow[b]{2}{*}{ SD } \\
\hline & 1 & 2 & 3 & 4 & 5 & 6 & 7 & & \\
\hline $\begin{array}{l}\text { Getting statistics on my mobility footprint (weekly } \\
\text { energy consumption and } \mathrm{CO}_{2} \text { emissions) }\end{array}$ & 0 & 0 & 2 & 4 & 6 & 8 & 5 & 5.40 & 1.23 \\
\hline $\begin{array}{l}\text { Getting statistics on my mobility patterns (weekly } \\
\text { kilometers, transport modes, travelling time) }\end{array}$ & 1 & 0 & 0 & 5 & 8 & 8 & 3 & 5.20 & 1.29 \\
\hline Potential for change (alternatives) & 0 & 1 & 2 & 9 & 5 & 5 & 2 & 4.71 & 1.27 \\
\hline Setting a personal goal for change & 3 & 0 & 1 & 7 & 7 & 4 & 3 & 4.56 & 1.71 \\
\hline Engaging in challenges against myself & 3 & 2 & 3 & 3 & 5 & 4 & 5 & 4.48 & 2.02 \\
\hline Being part of a community & 2 & 2 & 3 & 5 & 6 & 5 & 2 & 4.36 & 1.57 \\
\hline Receiving unexpected badges & 2 & 3 & 2 & 5 & 7 & 3 & 3 & 4.32 & 1.77 \\
\hline Comparing my performances with other app users & 2 & 4 & 4 & 5 & 3 & 5 & 2 & 4.04 & 1.81 \\
\hline
\end{tabular}

\subsection{Providing Information}

Either directly in the app or in the separate PDF report, GoEco! provided individuals with information on their baseline mobility patterns, on overall individual potential for change and on specific alternatives for systematic loops. As answers to the questionnaire show (see Table 6), getting to know one's potential for change was assessed as very interesting $(M=5.93, S D=1.12$, on a seven-point Likert scale), although this was not always sufficient to activate a critical reflection on one's mobility patterns $(M=4.80, S D=1.58)$, and even less to persuade to try the suggested alternatives out $(M=3.51$, 
$\mathrm{SD}=1.94)$ or start to regularly use them $(\mathrm{M}=3.11, \mathrm{SD}=2.07)$. According to some interviewees, the lack of action following the information on the potential for change was due to practical difficulties in implementing the suggested public transport or bicycle alternatives ("how could I satisfy all my family requirements, accompanying the kids and also carrying weights?", T2). Other interviewees, however, remarked that the lack of action could have been overcome by a more effective notification system: "often those are excuses, rather than real impeding factors" (T4). "For me, there were not enough and timely notifications to keep me going" (Z1). Particularly, notifications reminding users about possible alternatives for a given route, soon after that route was detected, would have been appreciated as useful triggers to support app users in at least trying the alternatives out. Even more useful from the users' point of view would have been the possibility to ask GoEco! for information on available alternatives for specific routes: "GoEco! was lacking in providing me with practical support when I was looking for alternatives to car use: I do not need to know the alternatives for a trip I have already taken! I need to know the available alternatives before I start a new trip" (T4). Namely, users asked for a multi-modal travel planning system, such as, for example, the one already offered by the Peacox persuasive app [50]. Endowing the app with such a component would also increase the frequency of user interactions with the app ("whenever I need to reach a different destination than usual, I would open the app", T4), thus also addressing one of the key problems affecting the Action and Maintenance stages, that is the risk of abandoning the app early, with consequent relapse to past mobility patterns.

\subsection{Providing Goal Setting Opportunities}

As indicated in Section 1.2, the provision of goal setting opportunities is acknowledged as an essential feature to trigger a change in individual behaviour. However, the average assessment of the goal setting feature was equal to $\mathrm{M}=4.56, \mathrm{SD}=1.71$ (Table 5). Additionally, as reported in Table 6, users stated they were only slightly motivated by the opportunity to set a goal $(\mathrm{M}=4.42, \mathrm{SD}=1.56$, on a seven-point scale) and they were even less eager to know whether, at the end of the week, they had achieved their goal or not $(\mathrm{M}=4.38, \mathrm{SD}=2.02)$. Goals were in fact judged to "quickly get boring" (Z2), since they were still seen as quite generic and impersonal: "it reminds me of those eating apps, where you always have to type what you eat: they are also rather boring" (Z2). "Instead, the app should have asked something like: 'Your friends drive by car so much, and use the bicycle so often. Would you like to do something similar?' And thus, tailor goals to people" (Z5). (Note that the idea of directly referring to the behaviour of other app users, which evokes a sense of belonging to a community, is discussed in Section 4.6.)

More variety was indeed offered in GoEco! by challenges, which were designed to provide users with a number of practical suggestions towards achievement of their goals for change. As shown in Table 5, however, challenges were poorly assessed as well $(\mathrm{M}=4.48, \mathrm{SD}=2.02)$. Particularly, users reported that challenges provided them with limited support towards achievement of their individual goal $(\mathrm{M}=4.13, \mathrm{SD}=1.90)$ and played a limited role in activating a critical reflection on their own mobility patterns $(\mathrm{M}=4.38, \mathrm{SD}=2.08)$ (Table 6$)$. Furthermore, even though challenges were not assessed as particularly boring or incompatible with individual constraints on mobility (respectively, $\mathrm{M}=2.83, \mathrm{SD}=1.31$ and $\mathrm{M}=3.54, \mathrm{SD}=1.87$ ), users tended not to replicate the new behaviour suggested by a challenge, once it had ended $(\mathrm{M}=3.88, \mathrm{SD}=1.75)$.

Again, interviewees lamented challenges were still too repetitive: "for a short time, a challenge is okay. In the long run, it gets boring, especially as it does not change and it is not personalised" (Z3). To avoid that boredom leads individuals to abandon the challenge and forget about it, they suggested to replace the current static, time-based notification system (one notification in the middle of the challenge and one at the conclusion of the challenge), with a dynamic one, based on user performance: "people should receive notifications depending on their progress towards challenge achievement. Particularly, you could send a notification when only little is missing to complete a challenge, such as: you only need to do another $500 \mathrm{~m}$ to achieve your challenge" (T6).

Also, some users suggested to explicitly present the potential benefits individuals could get by completing a challenge: "there is a difference between saying 'do that, it's a challenge' and 'do that, you save 
ten minutes'. These challenges are too general" (Z2). Finally, many users noted they would have expected "more timely and personalised challenges" (Z8): "since I couldn't increase my bicycle use anymore, I shouldn't have been shown bicycle-related challenges" (Z3) and "I would like to be able to start my own challenges" (Z8).

Table 6. Assessment of GoEco! features, based on a seven-point Likert scale, where 1 = "Strongly disagree" and $7=$ "Strongly agree". The number of answers depends on the question.

\begin{tabular}{|c|c|c|c|c|c|c|c|c|c|}
\hline & 1 & 2 & 3 & 4 & 5 & 6 & 7 & $\mathbf{M}$ & SD \\
\hline \multicolumn{10}{|l|}{ Baseline and potential mobility patterns } \\
\hline I was interested in knowing about my potential for change & 0 & 0 & 1 & 5 & 8 & 13 & 8 & 5.93 & 1.12 \\
\hline $\begin{array}{l}\text { The report stimulated me to critically reflect on my } \\
\text { mobility patterns }\end{array}$ & 1 & 3 & 5 & 8 & 13 & 6 & 8 & 4.80 & 1.58 \\
\hline I tried out the alternatives suggested by the reports & 11 & 4 & 5 & 8 & 7 & 6 & 2 & 3.51 & 1.94 \\
\hline $\begin{array}{l}\text { I'm now regularly using some alternatives suggested by } \\
\text { the reports }\end{array}$ & 17 & 2 & 6 & 8 & 4 & 3 & 4 & 3.11 & 2.07 \\
\hline \multicolumn{10}{|l|}{ Goals } \\
\hline The meaning of the goal for change was clear to me & 1 & 1 & 3 & 2 & 5 & 4 & 8 & 5.21 & 1.79 \\
\hline $\begin{array}{l}\text { I was stimulated to change my mobility patterns in order } \\
\text { to achieve my goal }\end{array}$ & 1 & 2 & 3 & 7 & 3 & 7 & 1 & 4.42 & 1.56 \\
\hline $\begin{array}{l}\text { I was eager to know if, at the end of the week, I had } \\
\text { achieved my goal }\end{array}$ & 3 & 3 & 2 & 2 & 5 & 6 & 3 & 4.38 & 2.02 \\
\hline \multicolumn{10}{|l|}{ Challenges } \\
\hline Challenges helped me to achieve my goal for change & 4 & 1 & 3 & 4 & 6 & 4 & 2 & 4.13 & 1.90 \\
\hline $\begin{array}{l}\text { Challenges made me critically reflect on my mobility } \\
\text { patterns }\end{array}$ & 4 & 2 & 2 & 1 & 6 & 6 & 3 & 4.38 & 2.08 \\
\hline Challenges were boring: they did not stimulate me at all & 4 & 6 & 7 & 5 & 1 & 1 & 0 & 2.83 & 1.31 \\
\hline $\begin{array}{l}\text { Challenges were not compatible with the constraints } \\
\text { affecting my mobility choices }\end{array}$ & 4 & 5 & 2 & 5 & 5 & 1 & 2 & 3.54 & 1.87 \\
\hline $\begin{array}{l}\text { After engaging in a challenge, I kept replicating the } \\
\text { mobility patterns suggested by the challenge }\end{array}$ & 4 & 1 & 4 & 5 & 6 & 3 & 1 & 3.88 & 1.75 \\
\hline \multicolumn{10}{|l|}{ Hall of Fame } \\
\hline $\begin{array}{l}\text { The way the ranking in the Hall of fame was computed } \\
\text { was clear to me }\end{array}$ & 3 & 3 & 4 & 6 & 2 & 3 & 1 & 3.64 & 1.73 \\
\hline $\begin{array}{l}\text { I checked my ranking in the Hall of fame every week, } \\
\text { to see my progress compared to the other participants }\end{array}$ & 7 & 4 & 2 & 2 & 3 & 3 & 2 & 3.30 & 2.16 \\
\hline $\begin{array}{l}\text { Apparently, no significant changes occurred in the } \\
\text { rankings, so I stopped regularly checking the Hall of fame }\end{array}$ & 2 & 3 & 1 & 8 & 3 & 4 & 0 & 3.90 & 1.58 \\
\hline $\begin{array}{l}\text { I was stimulated to modify my mobility patterns, in order } \\
\text { to achieve a top ranking in the Hall of fame }\end{array}$ & 8 & 3 & 4 & 3 & 1 & 2 & 2 & 3.00 & 2.05 \\
\hline
\end{tabular}

\subsection{Providing Feedback}

Notwithstanding the positive assessment of features providing feedback in Table 5, many interviewees noted the eco-feedback information was not fully meaningful to them, since they were not used to quantities such as tons of $\mathrm{CO}_{2}$ or kilowatt-hours. "It's true I could still check my progress over time, by comparing one week to the other, though I would have preferred to intuitively guess the very meaning of the numbers shown by GoEco: what do 10 kilograms of $\mathrm{CO}_{2}$ really mean?" (T4). To make those numbers more intuitive and immediately understandable, interviewees suggested to evoke their meaning through metaphors and comparisons with other well known variables. For instance, "you could back kWh up with gasoline litres" (T10) or "relate tons of $\mathrm{CO}_{2}$ with other activities we are used to perform at home-for example, what about providing us with the amount of corresponding washing machine cycles?" (T1) Others suggested to directly avoid the provision of numerical feedback ("people do not like to see numbers" (Z5), and "replace it with a graphical visualisation of the size of the impact" (T1), such as, for example, the UbiGreen app [54]. Finally, some interviewees suggested to focus on the avoided impact, instead of the actually produced one, such as, for example, "thanks to your use of the bicycle today, xxx litres of oil have not been consumed" (T5) or "the $\mathrm{CO}_{2}$ emissions you saved are equal to yyy trees being planted" 
(T10). However, we would be careful in embracing this approach, since it stands in disagreement with the basic behavioural economics principle about loss aversion: behaviour change is better stimulated if people perceive the dis-utility of having lost something, instead of the utility of having gained something [94-96]. Actually, from this point of view, providing users with feedback in terms of the distance to their own potential for change would have probably been more effective.

Some users suggested they would have also appreciated other types of feedback, such as monetary, health or time-savings feedback. The idea here is to offer all these types of feedback, letting the user choose the ones better fitting with her own system of values-an approach that was adopted by the enCOMPASS persuasive app in the domain of energy saving in households [97]. For instance, some users suggested to provide feedback in terms of the monetary costs per kilometre travelled (holistically estimated using life cycle assessment, and not only direct use costs), the frequency of gasoline refuelling needs, or the lifespan of one's own car. "For example, you could tell people that, if they keep using the car for short trips, they would need to replace it after, say, just seven years, instead of ten years. This might lead them to reflect on their daily patterns and stimulate them to change" (T4).

In addition, interviewees suggested that such a monetary feedback could focus on the collective level, instead of just highlighting individual benefits or costs: "I would like to know whether-and how much - my mobility choices contribute to savings of road maintenance costs. For example, something like: highways need to be tarmacked every year, secondary roads every twenty years. With your low-car dependent patterns, you allowed the Swiss Confederation to save xxx francs for tarmacking" (T5). Such feedback, however, would only make sense over a long time-span, such as on a yearly basis.

Finally, the interviews also highlighted the difficulty of getting an overall evaluation of one's performance, based on the provided feedback: "whatever the unit of measurement, what is the level of the environmental impact I am producing? I would have liked to receive some 'red/green light' indications, or at least to know if I am better or worse than average" (Z1).

\subsection{Providing Rewards or Punishments}

According to the general GoEco! assessment shown in Table 5, intangible rewards such as badges are judged as limited in stimulating more sustainable mobility patterns (respectively, $\mathrm{M}=4.32, \mathrm{SD}=1.77$ and $\mathrm{M}=3.92, \mathrm{SD}=1.82$ ). Some interviewees suggested that rewards could be made tangible, instead of virtual, but if so, they should be collective, instead of individual: "for example, you could do something like the Ecosia search engine (https://www.ecosia.org): your actions contribute to planting a number of trees. Similarly, I would like to get a badge notifying me I have contributed to saving a certain amount of $\mathrm{CO}_{2}$ emissions and that as a reward a number of trees will be planted somewhere in the world" (T10). The low interest for individual, in-kind prizes reflects currently acknowledged behavioural economics principles, according to which intrinsic rewards (such as recommendations, public recognition, and praise) may have stronger and more consistent behavioural effects than monetary rewards, which in some cases might even paradoxically end up discouraging an implementation of the new behaviour [94-96]. Nonetheless, the low interest for tangible, individual rewards might also be due to the fact that the majority of project participants had voluntarily applied to join the GoEo! project: indeed, we suppose most of them already had an intrinsic motivation to actively try to change their behaviour-namely, they were already in the contemplation stage according to the transtheoretical model, and therefore the possibility to earn a prize only influenced them to a limited extent. We cannot exclude, however, that less motivated individuals, such as the majority of those being in the pre-contemplation stage, could be attracted by the availability of tangible prizes. In addition, we are aware that such a low interest for individual tangible prizes could be due to the fact that Switzerland, ranked second worldwide in the Human Development Index in 2018 [98], is a wealthy country, where on average people enjoy very high standards of living. Previous research at the international level summarised by Habibipour et al. [99] reports in fact that building a long-term commitment between an ICT-based system and its users requires a proper economic reward. Therefore, in future research activities one could exploit individual, tangible prizes, to start engaging individuals 
with low intrinsic motivation towards change (individuals in the pre-contemplation stage), and gradually replace prizes by other motivational factors, as long as the individuals progress through the stages of behaviour change.

The use of punishment was not explored in GoEco!, due to the negative connotation it is usually associated with [32]. An interviewee, however, suggested that badge-like elements could be used not only to mark detection of particularly sustainable choices, but also to notify their absence. Namely, she suggested to build on one's sense of guilt—-though avoiding any direct punishment or penalty: "for example, you could remind users of something like: you have not been using the bus in quite a while. What happened?" (T1) Such a notification would actually be coherent with the loss aversion behavioural economics principle mentioned above (since it implies that by not using the bus, the user has lost something), therefore it is particularly worth being explored.

\subsection{Providing Occasions for Social Comparisons}

Opportunities for social comparison were provided by weekly statistics in the Hall of Fame section. The overall effectiveness of the Hall of Fame feature was assessed as rather low, as indicated in Table $5(\mathrm{M}=4.04, \mathrm{SD}=1.81)$ and in Table 6: possible doubts on how the ranking was computed ("the computation was clear to me" $\mathrm{M}=3.64, \mathrm{SD}=1.73$ ), together with a perceived lack of dynamism $(\mathrm{M}=3.90, \mathrm{SD}=1.58)$, contributed to reducing the interest of users towards regularly checking it $(\mathrm{M}=3.30, \mathrm{SD}=2.16)$, thus largely affecting its capability to stimulate a change in individual mobility patterns $(\mathrm{M}=3.00, \mathrm{SD}=2.05)$.

The lack of dynamism was partially due to technical problems, which prevented the Hall of Fame feature from working correctly for a certain period, and probably negatively affected these evaluations. Interviewees, however, did not stress this aspect, focusing instead on how to make the comparison metrics more meaningful to them. For instance, they suggested to rank app users based on weekly absolute individual performances, such as "the user who saved more petrol in absolute values over the week or the user who consumed less petrol, in absolute values, over the week" (T5). However, they also noted that such rankings should only be made between users with reciprocally comparable profiles, for instance in terms of the average commuting distance, other constraints affecting individual mobility choices, and available alternatives to car use, instead of considering all app users: "if I am used to travel $4000 \mathrm{~km}$ by car every month, and I win a car-reducing challenge, are my efforts lower, higher or the same as people travelling $400 \mathrm{~km}$ by car every month, and winning the same trophy? If other people start from more favourable conditions than mine, but we are rewarded with the same trophy, we are ranked equally in the leaderboard. I perceive this as unfair and soon lose interest in it" (T6).

We were well aware of this risk, which also holds for the other elements used to compute the ranking in the leaderboard, and especially for the percentage of achievement of the individual goal for change. In fact, since GoEco! is not capable of automatically profiling app users based on the practical constraints affecting their current mobility needs and potentials for change, it cannot assess the level of difficulty a certain behaviour has for them. From our perspective, introducing any super-imposed "rating of difficulty" would create more unfairness than the one we were trying to overcome. Therefore, we explicitly opted for letting the users choose for themselves, in the belief they are genuinely acting at the best of their possibilities: app users are invited to set the best goal for them and to freely join the challenge(s) they assess as most suitable to their possibilities, if any, in a relationship of trust among each other and with the system. And indeed, considering there are no tangible prizes, they would have no reasons for cheating the system and opting for too easy targets and challenges on purpose.

However, this approach was not fully understood and appreciated: other ways to exploit social interactions to favour user engagement in the behaviour change process should be sought.

\subsection{From a Set of Individual Users to a Community of Users}

While the above features, allowing individuals to compare themselves with the other users, were poorly appreciated, the interviews highlighted users were highly interested in additional features 
involving social interactions. Namely, they suggested to overcome the current focus on the individual level and to increase the feeling of belonging to a community, which was reported as pretty low (Table 5), also due to the lack of pre-existing relationships among app users. This is also suggested by a whole branch of research that acknowledges "low-carbon communities", either place-based or virtual ones, as the necessary framework to support behaviour change at the individual level (see for example [100]).

For instance, users would have appreciated possibilities for direct interaction with other app users, via an internal chat or forum, or even an external social network, to share individual performance, success and failure. Namely, the participants would have benefited from a social space to get to know each other, as suggested by Habibipour et al. [99]. Then, they would have liked to create new challenges and to invite other app users to join them: "and if I start a new challenge, I would also like to get a (nearly real-time) feedback about how I am behaving with respect to them: am I better or worse?" (Z1)

Some interviewees also suggested users could share the routes they travel with a circle of friends. Allowing users to share their data with a selected circle of friends would in turn allow leveraging the behaviour of other users. For example, the app could give visibility to exemplary users, when they manage to address their daily mobility challenges: "in Zurich it is very hilly, rainy, cold, and people have luggage and kids. You have to show that there are real people that indeed manage to use the bike even though they have luggage and kids and it is raining! If you find them, you could show their performances to everyone, presenting them as the 'idols' of the community" (Z7). In addition, as already suggested in Section 4.2, one could tailor a user's individual goal for change, based on specific mobility patterns of other users. Or something such as "a GoEco!-Tinder feature could even be created [Tinder is a dating app, https:/ / tinder.com, Ed.], matching people who like someone else's travel style" (Z4).

Including this concept of a circle of friends, challenges could also be made more fun, such as "Who goes furthest with an e-bike?" (Z7). Interviewees were asked whether the circle of friends they envisioned should be better composed of pre-existing friends in real life. There was no agreement on this point: on the one hand "if you interact with friends, the message can easily be amplified: you might be lead to discuss about the app, and thus your mobility patterns, also when you meet your friends for a dinner or a cocktail. And if, just like me, you have a competitive attitude, you would really do all your best to beat a friend!" (T6). However, on the other hand "if I just talk with my circle of friends, I would not be too much stimulated to change... I would also appreciate knowing about someone else" (T11). Moreover, "indeed, competitors should frequently change: every week you should be able to compete against different people" (Z3). Therefore, the conclusion would be, once again, to leave app users the choice whether interacting with just their real-life friends or also with strangers that the app has identified as potential "matching friends", based on a few user profiling questions, asked at registration. The challenge remains, however, about how to profile app users so that their actual constraints and potential for change are properly taken into account and suggested matching is meaningful.

Finally, the interviews allowed exploring the idea of a "team-based" approach, namely creating teams of individuals and inviting them to collaborate in order to achieve a given common goal for change or to compete against another team, always in terms of change with respect to baseline mobility patterns. Even though this approach was positively assessed in the context of energy saving in households, such as in the Social Power project [101], GoEco! interviewees did not appreciate it, due to the difficulty of building balanced teams with both comparable mobility needs and accessibility to alternatives to car and already existing real-life relationships capable of creating an enduring commitment. However, interviewees saw a potential within corporate mobility management processes: "you could try this approach with companies: relations between individuals would already be in place (such as colleagues of the same office, division, or building), and, with at least one destination in common (the workplace), individuals would at least partially have similar mobility constraints and opportunities" (T1). Indeed, even though with a specific focus on cycling, only involving commuting trips, and without the support of automatic mobility tracking tools, a similar approach has long and successfully been experimented in Switzerland, through the "Bike to Work" challenge that was first launched in 2005 
(http://biketowork.com). In the future, an integration between GoEco! and Bike to Work could therefore be envisioned.

\section{Conclusions}

In this paper, we presented an attempt to overcome the main limitations that were found to affect behaviour change apps targeting more sustainable individual mobility patterns. Particularly, we focused on the lack of grounding in a behaviour change theory and on the over-reliance on one-size-fits-all, point-based reward mechanics that typically occur when gamification approaches are exploited. To this purpose, we developed an app, named GoEco!, and opted for grounding it in the transtheoretical model for behaviour change.

Instead of primarily relying on a standardised point-based reward system, the app's features and components were designed with the specific aim of assisting individual progress from one stage of the behaviour change process to the next one, through activation of the proper process(es) of change at each stage. Namely, specific app features were designed for each stage, from pre-contemplation of behaviour change to maintenance of a new, more sustainable, behaviour, and, to increase their effectiveness, a user-centred approach was adopted.

The app effectiveness was then field-tested by 47 voluntary users in a three-month experiment in two Swiss regions. After the experiment, we ran a survey and interviews to get insights on the app's features and components directly from its users. In general, the users expressed the desire for further customisation (regarding potential for change, available alternatives, goals, challenges and notifications), as well as further simplification concerning the number of offered features. Based on this experience, we therefore recommend that future persuasive apps better follow the process of behaviour change, by releasing the app features in stages as well: at registration, a simple question such as the one proposed by Bamberg [78] could allow to classify the users' initial stage of behaviour change. Then, users could only be offered the app features specifically designed for their stage. For example, a user in the pre-contemplation stage should only receive feedback on each travelled route and on her baseline mobility patterns, while a user in the action phase should have all the app features enabled (in both cases with a proper on-boarding training period). Then, the classifying question should be periodically repeated, and new features should be released when progress to the next stage is detected.

More specifically, this experience provides us with practical suggestions to further improve the recommendations for effective persuasive apps that were identified in previous works:

- Provide information: Improve the automatic detection capability of both travelled routes and transport modes to reduce the need for manual validation of the transport mode by the users. In addition, endow the app with a multi-modal travel planning system, capable of actively supporting users in their daily travel needs, especially for non-systematic trips. Such a component would not only provide them with additional practical information useful in their process of change, but would also increase the frequency of their interaction with the app, thus helping them to remain committed to their goals and challenges.

- Provide goal setting opportunities: Allow for as much customisation and dynamism as possible, in both goals and challenges, by developing a timely notification system based on user performances and by explicitly referring to specific mobility patterns of other app users in the design of goals and challenges themselves.

- Provide feedback: Make individual impact more intuitive and immediately understandable (for example, by exploiting visualisation techniques instead of purely numerical values), as well as more diversified (for instance, by offering information on health and monetary impacts, besides the current energy and climate ones).

- Provide rewards or punishments: Provide tangible rewards, both at the individual level (mainly targeting individuals in the pre-contemplation stage, as a lure to raise their interest in the app, and thus activate their process of change), and at the community level (to keep the interest of those who are already in the next stages of behaviour change). 
- Provide occasions for social comparison: Better exploit the power of social interactions. Instead of limiting comparisons to behavioural aspects, which is difficult to perform in a fair way and risks not to be trusted, let the app include features and components aimed at increasing the perception of social support and the feeling of belonging to a community of similar people, engaged together towards the same goal for change. Namely, move the focus from a competitive setting to helping relationships. To this purpose, include features allowing users to share activities and performances, such as for example comments, questions, travelled routes, average mobility patterns, challenges, and so on.

Even though these suggestions entirely originate from a process developed in Switzerland, one of the top-three countries worldwide according to the Human Development Index, we believe they are only marginally influenced by the Swiss high standards of living. In lower income countries, we expect even higher interest for tangible rewards at the individual level, and suppose recommendations on the other aspects would maintain their effectiveness. A fundamental prerequisite for the effectiveness of a persuasive app such as GoEco!, however, is the accessibility to realistic alternatives to individual car use, such as timely and frequent public transport and safe and widespread cycling and walking paths. In lower income countries, where these options might be lacking, this would be a major constraint precluding the effectiveness of similar persuasive approaches, no matter whether the above recommendations have been put into practice.

Implementing all the above suggestions will require further research efforts in different disciplines, from artificial intelligence for automatic transport mode detection, travel planning information and better customisation (alternatives, potentials, notification, etc.), to user interface design (visualisation of the impact), and social and behavioural sciences (improvement of social support and a feeling of community). The route for effective persuasive apps in the mobility sector is therefore still long. We hope, however, with this work, to have identified in which direction the steps forward need to be taken.

Author Contributions: Conceptualisation, F.C., D.B., R.R., and M.R.; Methodology, F.C. and D.B.; Formal Analysis, F.C., D.B., and J.V.S.; Writing-Original Draft Preparation, F.C.; Writing-Review and Editing, D.B., J.V.S., M.R., and R.R.; and Supervision, R.R., M.R.

Funding: This research was supported by the Swiss National Science Foundation (SNF) within NRP 71 "Managing energy consumption" and is part of the Swiss Competence Center for Energy Research SCCER Mobility of the Swiss Innovation Agency Innosuisse.

Acknowledgments: We thank all researchers involved in the GoEco! project who do not figure among the authors of this paper, as well as the supporting institution that helped us throughout the project. Finally, we are very grateful to all citizens who actively engaged with us in the GoEco! field activities in Zurich and Canton Ticino.

Conflicts of Interest: The authors declare no conflict of interest. The founding sponsors had no role in the design of the study; in the collection, analyses, or interpretation of data; in the writing of the manuscript, and in the decision to publish the results.

\section{References}

1. Diekstra, R.; Kroon, M. Cars and behaviour: Psychological barriers to car restraint and sustainable urban transport. In The Greening of Urban Transport: Planning for Walking And Cycling in Western Cities; John Wiliy \& Sons Ltd.: Hoboken, NJ, USA, 1997.

2. Stopher, P.R. Reducing road congestion: A reality check. Transp. Policy 2004, 11, 117-131. [CrossRef]

3. Steg, L. Car use: Lust and must. Instrumental, symbolic and affective motives for car use. Transp. Res. Part A Policy Pract. 2005, 39, 147-162. [CrossRef]

4. Urry, J. The 'system' of automobility. Theory Cult. Soc. 2004, 21, 25-39. [CrossRef]

5. Kramers, A. Designing next generation multimodal traveler information systems to support sustainability-oriented decisions. Environ. Model. Softw. 2014, 56, 83-93. [CrossRef]

6. Steg, L.; Tertoolen, G. Sustainable transport policy: The contribution from behavioural scientists. Public Money Manag. 1999, 19, 63-69. [CrossRef]

7. Chatterjee, K.; Bonsall, P. Editorial for special issue on 'Evaluation of programmes promoting voluntary change in travel behaviour'. Transp. Policy 2009, 16,6, 279-280. [CrossRef] 
8. Arnott, B.; Rehackova, L.; Errington, L.; Sniehotta, F.F.; Roberts, J.; Araujo-Soares, V. Efficacy of behavioural interventions for transport behaviour change: systematic review, meta-analysis and intervention coding. Int. J. Behav. Nutr. Phys. Act. 2014, 11, 133. [CrossRef] [PubMed]

9. Banister, D.; Stead, D. Impact of information and communications technology on transport. Transp. Rev. 2004, 24, 611-632. [CrossRef]

10. Gössling, S. ICT and transport behavior: A conceptual review. Int. J. Sustain. Transp. 2018, 12, $153-164$. [CrossRef]

11. Nam, T.; Pardo, T.A. Conceptualizing smart city with dimensions of technology, people, and institutions. In Proceedings of the 12th Annual International Digital Government Research Conference: Digital Government Innovation in Challenging Times, College Park, MD, USA, 12-15 June 2011; ACM: New York, NY, USA, 2011; pp. 282-291.

12. Goldsmith, S.; Crawford, S. The Responsive City: Engaging Communities Through Data-Smart Governance; John Wiley \& Sons: Hoboken, NJ, USA, 2014.

13. Fogg, B. Persuasive Technology: Using Computers to Change What We Think and Do (Interactive Technologies); Morgan Kaufmann: Burlington, MA, USA, 2002.

14. Darby, S. Making it obvious: Designing feedback into energy consumption. In Energy Efficiency in Household Appliances and Lighting; Springer: Berlin/Heidelberg, Germany, 2001; pp. 685-696.

15. Darby, S. The Effectiveness of Feedback on Energy Consumption; A Review for Defra of the Literature on Metering, Billing and Direct Display; 2006; Volume 486, p. 26. Available online: https:/ /www.eci.ox.ac.uk/ research/energy/downloads/smart-metering-report.pdf (accessed on 15 April 2019).

16. Darby, S. Smart metering: What potential for householder engagement? Build. Res. Inf. 2010, 38, 442-457. [CrossRef]

17. Fischer, C. Feedback on household electricity consumption: A tool for saving energy? Energy Effic. 2008, 1, 79-104. [CrossRef]

18. Burgess, J.; Nye, M. Re-materialising energy use through transparent monitoring systems. Energy Policy 2008, 36, 4454-4459. [CrossRef]

19. Sergici, S.; Faruqui, A. Measurement and Verification Principles for Behavior-Based Efficiency Programs; Brattle Group: Cambridge, MA, USA, 2011.

20. Hargreaves, T.; Nye, M.; Burgess, J. Making energy visible: A qualitative field study of how householders interact with feedback from smart energy monitors. Energy Policy 2010, 38, 6111-6119. [CrossRef]

21. Hargreaves, T.; Nye, M.; Burgess, J. Keeping energy visible? Exploring how householders interact with feedback from smart energy monitors in the longer term. Energy Policy 2013, 52, 126-134. [CrossRef]

22. Weiss, M.; Loock, C.M.; Staake, T.; Mattern, F.; Fleisch, E. Evaluating mobile phones as energy consumption feedback devices. In Proceedings of the International Conference on Mobile and Ubiquitous Systems: Computing, Networking, and Services; Springer: Berlin/Heidelberg, Germany, 2010; pp. 63-77.

23. Fischli, C.; Staake, T.; Stiefmeier, T.; Tröster, G.; Fleisch, E. Energieeffizienz durch Verbrauchsfeedback bei der: Report zum Forschungsprojekt Amphiro-Smart Water Metering; Bits to Energy Lab: Zurich, Switzerland, 2011.

24. Schleich, J.; Klobasa, M.; Brunner, M.; Gölz, S.; Götz, K. Smart Metering in Germany and Austria: Results of Providing Feedback Information in a Field Trial; Technical Report, Working Paper Sustainability and Innovation, No. S6/2011; Fraunhofer ISI: Karlsruhe, Germany, 2011.

25. Degen, K.; Efferson, C.; Frei, F.; Goette, L.; Lalive, R. Smart Metering, Beratung oder Sozialer Vergleich: Was Beeinflusst den Elektrizitätsverbrauch; Université de Lausanne: Lausanne, Switzerland, 2013.

26. Tiefenbeck, V.; Tasic, V.; Staake, T.; Goette, L. Real-time feedback and social dynamics in energy conservation. In Proceedings of the Behavior, Energy and Climate Change Conference (BECC 2013), Sacramento, CA, USA, 18-20 November 2013.

27. Tiefenbeck, V.; Tasic, V.; Schöb, S.; Degen, K.; Goette, L.; Fleisch, E.; Staake, T. Steigerung der Energieeffizienz durch Verbrauchsfeedback: Abschlussbericht der ewz-Amphiro-Studie; KTI / ETH: Zurich, Switzerland, 2013.

28. Novak, J.; Melenhorst, M.; Micheel, I.; Pasini, C.; Fraternali, P. Behaviour change and incentive modelling for water saving: First results from the SmartH2O project. In Proceedings of the The 8th International Congress on Environmental Modelling and Software, Toulouse, France, 10-14 July 2016; pp. 1-10.

29. Mankoff, J.; Matthews, D.; Fussell, S.R.; Johnson, M. Leveraging social networks to motivate individuals to reduce their ecological footprints. In Proceedings of the 2007 40th Annual Hawaii International Conference on System Sciences-HICSS 2007, Waikoloa, HI, USA, 3-6 January 2007; p. 87. 
30. Mankoff, J.; Fussell, S.R.; Dillahunt, T.; Glaves, R.; Grevet, C.; Johnson, M.; Matthews, D.; Matthews, H.S.; McGuire, R.; Thompson, R.; et al. StepGreen.org: Increasing Energy Saving Behaviors via Social Networks. In Proceedings of the ICWSM, Washington, DC, USA, 23-26 May 2010.

31. Foster, D.; Blythe, M.; Cairns, P.; Lawson, S. Competitive carbon counting: Can social networking sites make saving energy more enjoyable? In Proceedings of the CHI'10 Extended Abstracts on Human Factors in Computing Systems, Atlanta, GA, USA, 10-15 April 2010; ACM: New York, NY, USA, 2010; pp. 4039-4044.

32. Foster, D.; Linehan, C.; Lawson, S.; Kirman, B. Power ballads: Deploying aversive energy feedback in social media. In Proceedings of the CHI'11 Extended Abstracts on Human Factors in Computing Systems, Vancouver, BC, Canada, 7-12 May 2011; ACM: New York, NY, USA, 2011; pp. 2221-2226.

33. Froehlich, J.; Findlater, L.; Landay, J. The design of eco-feedback technology. In Proceedings of the SIGCHI Conference on Human Factors in Computing Systems, Atlanta, GA, USA, 10-15 April 2010; ACM: New York, NY, USA, 2010; pp. 1999-2008.

34. Lehrer, D.; Vasudev, J. Evaluating a social media application for sustainability in the workplace. In Proceedings of the CHI'11 Extended Abstracts on Human Factors in Computing Systems, Vancouver, BC, Canada, 7-12 May 2011; ACM: New York, NY, USA, 2011; pp. 2161-2166.

35. Petkov, P.; Köbler, F.; Foth, M.; Krcmar, H. Motivating domestic energy conservation through comparative, community-based feedback in mobile and social media. In Proceedings of the 5th International Conference on Communities and Technologies, Brisbane, Australia, 29 June-2 July 2011; ACM: New York, NY, USA, 2011; pp. 21-30.

36. Weiss, M.; Staake, T.; Mattern, F.; Fleisch, E. PowerPedia: Changing energy usage with the help of a community-based smartphone application. Pers. Ubiquitous Comput. 2012, 16, 655-664. [CrossRef]

37. Bull, R.; Irvine, K.N.; Rieser, M.; Fleming, P. Are people the problem or the solution? A critical look at the rise of the smart/intelligent building and the role of ICT enabled engagement. In Proceedings of the ECEEE Summer Study Conference, Belambra Les Criques, France, 3-8 June 2013; pp. 1135-1145.

38. Wemyss, D.; Castri, R.; De Luca, V.; Cellina, F.; Frick, V.; Lobsiger-Kägi, E.; Bianchi, P.G.; Hertach, C.; Kuehn, T.; Carabias, V. Keeping up with the Joneses: Examining community-level collaborative and competitive game mechanics to enhance household electricity-saving behaviour. In Proceedings of the 4th European Conference on Behaviour and Energy Efficiency, Coimbra, Portugal, 8-9 September 2016.

39. Deterding, S.; Sicart, M.; Nacke, L.; O'Hara, K.; Dixon, D. Gamification. Using game-design elements in non-gaming contexts. In Proceedings of the CHI'11 Extended Abstracts on Human Factors in Computing Systems, Vancouver, BC, Canada, 7-12 May 2011; ACM: New York, NY, USA, 2011; pp. 2425-2428.

40. Weiser, P.; Bucher, D.; Cellina, F.; De Luca, V. A taxonomy of motivational affordances for meaningful gamified and persuasive technologies. In Proceedings of the 3rd International Conference on ICT for Sustainability, Copenhagen, Denmark, 7-9 September 2015.

41. Schuessler, N.; Axhausen, K. Processing raw data from global positioning systems without additional information. Transp. Res. Record J. Transp. Res. Board 2015, 28-36. [CrossRef]

42. Kiukkonen, N.; Blom, J.; Dousse, O.; Gatica-Perez, D.; Laurila, J. Towards rich mobile phone datasets: Lausanne data collection campaign. In Proceedings of the ICPS, Berlin, Germany, 13-16 July 2010.

43. Nitsche, P.; Widhalm, P.; Breuss, S.; Maurer, P. A strategy on how to utilize smartphones for automatically reconstructing trips in travel surveys. Procedia-Soc. Behav. Sci. 2012, 48, 1033-1046. [CrossRef]

44. Ythier, J.; Walker, J.; Bierlaire, M. The Role of the Social Network and the Usage of Communication in Travel Behavior Measured with Smartphone Data; Technical Report, Technical Report TRANSP-OR 120801; Transport and Mobility Laboratory, ENAC- EPFL: Lausanne, Switzerland, 2012.

45. Raubal, M. Cogito ergo mobilis sum: The impact of location-based services on our mobile lives. In The SAGE Handbook of GIS and Society; SAGE Publications Ltd.: Saunders Oaks, CA, USA, 2011; pp. 159-173.

46. Yuan, Y.; Raubal, M. Extracting dynamic urban mobility patterns from mobile phone data. In Proceedings of the International Conference on Geographic Information Science; Springer: Berlin/Heidelberg, Germany, 2012; pp. 354-367.

47. Yuan, Y.; Raubal, M.; Liu, Y. Correlating mobile phone usage and travel behavior-A case study of Harbin, China. Comput. Environ. Urban Syst. 2012, 36, 118-130. [CrossRef]

48. Cellina, F.; Förster, A.; Rivola, D.; Pampuri, L.; Rudel, R.; Rizzoli, A.E. Using smartphones to profile mobility patterns in a living lab for the transition to e-mobility. In Proceedings of the International Symposium on Environmental Software Systems; Springer: Berlin/Heidelberg, Germany, 2013; pp. 154-163. 
49. Jariyasunant, J.; Abou-Zeid, M.; Carrel, A.; Ekambaram, V.; Gaker, D.; Sengupta, R.; Walker, J.L. Quantified traveler: Travel feedback meets the cloud to change behavior. J. Intell. Transp. Syst. 2015, 19, 109-124. [CrossRef]

50. Bothos, E.; Mentzas, G.; Prost, S.; Schrammel, J.; Röderer, K. Watch your Emissions: Persuasive Strategies and Choice Architecture for Sustainable Decisions in Urban Mobility. Psychnol. J. 2014, 12, $23-25$.

51. Wells, S.; Kotkanen, H.; Schlafli, M.; Gabrielli, S.; Masthoff, J.; Jylhä, A.; Forbes, P. Towards an Applied Gamification Model for Tracking, Managing, \& Encouraging Sustainable Travel Behaviours. ICST Trans. Ambient Syst. 2014, 1, e2. [CrossRef]

52. Jylhä, A.; Nurmi, P.; Sirén, M.; Hemminki, S.; Jacucci, G. Matkahupi: A persuasive mobile application for sustainable mobility. In Proceedings of the 2013 ACM Conference on Pervasive and Ubiquitous Computing Adjunct Publication, Zurich, Switzerland, 8-12 September 2013; ACM: New York, NY, USA, 2013; pp. 227-230.

53. Bie, J.; Bijlsma, M.; Broll, G.; Cao, H.; Hjalmarsson, A.; Hodgson, F.; Holleis, P.; van Houten, Y.; Jacobs, K.; Koolwaaij, J.; et al. Move better with Tripzoom. Int. J. Adv. Life Sci. 2012, 4, 125-135.

54. Froehlich, J.; Dillahunt, T.; Klasnja, P.; Mankoff, J.; Consolvo, S.; Harrison, B.; Landay, J.A. UbiGreen: Investigating a mobile tool for tracking and supporting green transportation habits. In Proceedings of the SIGCHI Conference on Human Factors in Computing Systems, Boston, MA, USA, 4-9 April 2009; ACM: New York, NY, USA, 2009; pp. 1043-1052.

55. Oinas-Kukkonen, H. A foundation for the study of behavior change support systems. Pers. Ubiquitous Comput. 2013, 17, 1223-1235. [CrossRef]

56. Froehlich, J. Gamifying green: Gamification and Environmental Sustainability. In The Gameful World: Approaches, Issues, Applications; Walz, S.P., Deterding, S., Eds.; MIT Press: Cambridge, MA, USA, 2015.

57. Anagnostopoulou, E.; Bothos, E.; Magoutas, B.; Schrammel, J.; Mentzas, G. Persuasive technologies for sustainable urban mobility. arXiv 2016, arXiv:1604.05957.

58. Ryan, R.M.; Deci, E.L. Intrinsic and extrinsic motivations: Classic definitions and new directions. Contemp. Educ. Psychol. 2000, 25, 54-67. [CrossRef]

59. Oinas-Kukkonen, H.; Harjumaa, M. Persuasive systems design: Key issues, process model, and system features. Commun. Assoc. Inf. Syst. 2009, 24, 28. [CrossRef]

60. Abraham, C.; Michie, S. A taxonomy of behavior change techniques used in interventions. Health Psychol. 2008, 27, 379-387. [CrossRef]

61. Shaheen, S.; Cohen, A.; Zohdy, I.; Kock, B. Smartphone Applications to Influence Travel Choices: Practices and Policies; Technical Report; U.S. Department of Transportation, Federal Highway Administration: Washington, DC, USA, 2016.

62. Sunio, V.; Schmöcker, J.D. Can we promote sustainable travel behavior through mobile apps? Evaluation and review of evidence. Int. J. Sustain. Transp. 2017, 11, 553-566. [CrossRef]

63. Anagnostopoulou, E.; Bothos, E.; Magoutas, B.; Schrammel, J.; Mentzas, G. Persuasive technologies for sustainable mobility: State of the art and emerging trends. Sustainability 2018, 10, 2128. [CrossRef]

64. Möser, G.; Bamberg, S. The effectiveness of soft transport policy measures: A critical assessment and meta-analysis of empirical evidence. J. Environ. Psychol. 2008, 28, 10-26. [CrossRef]

65. Michie, S.; Prestwich, A. Are interventions theory-based? Development of a theory coding scheme. Health Psychol. 2010, 29, 1-8. [CrossRef] [PubMed]

66. He, H.A.; Greenberg, S.; Huang, E.M. One size does not fit all: Applying the transtheoretical model to energy feedback technology design. In Proceedings of the SIGCHI Conference on Human Factors in Computing Systems, Atlanta, GA, USA, 10-15 April 2010; ACM: New York, NY, USA, 2010; pp. 927-936.

67. Huber, M.Z.; Hilty, L.M. Gamification and sustainable consumption: Overcoming the limitations of persuasive technologies. In ICT Tnnovations for Sustainability; Springer: Berlin/Heidelberg, Germany, 2015; pp. 367-385.

68. Brynjarsdottir, H.; Håkansson, M.; Pierce, J.; Baumer, E.; DiSalvo, C.; Sengers, P. Sustainably unpersuaded: How persuasion narrows our vision of sustainability. In Proceedings of the SIGCHI Conference on Human Factors in Computing Systems, Austin, TX, USA, 5-10 May 2012; ACM: New York, NY, USA, 2012, pp. 947-956.

69. Mols, F.; Haslam, S.A.; Jetten, J.; Steffens, N.K. Why a nudge is not enough: A social identity critique of governance by stealth. Eur. J. Political Res. 2015, 54, 81-98. [CrossRef] 
70. Prochaska, J.O.; Velicer, W.F. The transtheoretical model of health behavior change. Am. J. Health Promot. 1997, 12, 38-48. [CrossRef] [PubMed]

71. Gould, J.D.; Lewis, C. Designing for usability: Key principles and what designers think. Commun. ACM 1985, 28, 300-311. [CrossRef]

72. Norman, D.A.; Draper, S.W. User Centered System Design; New Perspectives on Human-Computer Interaction; L. Erlbaum Associates Inc.: Hillsdale, NJ, USA, 1986.

73. Grudin, J.; Pruitt, J. Personas, participatory design and product development: An infrastructure for engagement. In Proceedings of the PDC, Malmo, Sweden, 23-25 June 2002; p. 7.

74. Junior, P.T.A.; Filgueiras, L.V.L. User modeling with personas. In Proceedings of the 2005 Latin American Conference on Human-Computer Interaction, Cuernavaca, Mexico, 23-26 October 2005; ACM: New York, NY, USA, 2005; pp. 277-282.

75. Idoughi, D.; Seffah, A.; Kolski, C. Adding user experience into the interactive service design loop: A persona-based approach. Behav. Inf. Technol. 2012, 31, 287-303. [CrossRef]

76. Cellina, F.; Cavadini, P.; Soldini, E.; Bettini, A.; Rudel, R. Sustainable Mobility Scenarios in Southern Switzerland: Insights from Early Adopters of Electric Vehicles and Mainstream Consumers. Transp. Res. Procedia 2016, 14, 2584-2593. [CrossRef]

77. Hudson, W. User stories don't help users: Introducing persona stories. Interactions 2013, 20, 50-53. [CrossRef]

78. Bamberg, S. Applying the stage model of self-regulated behavioral change in a car use reduction intervention. J. Environ. Psychol. 2013, 33, 68-75. [CrossRef]

79. Cellina, F.; Bucher, D.; Rudel, R.; Raubal, M.; Rizzoli, A.E. Promoting Sustainable Mobility Styles using Eco-Feedback and Gamification Elements: Introducing the GoEco! Living Lab Experiment. In Proceedings of the 4th European Conference on Behaviour and Energy Efficiency (BEHAVE 2016), Coimbra, Portugal, 8-9 September 2016.

80. Hartman, R.S. Self-selection bias in the evolution of voluntary energy conservation programs. Rev. Econ. Stat. 1988, 70, 448-458. [CrossRef]

81. Tiefenbeck, V.; Wörner, A.; Schöb, S.; Fleisch, E.; Staake, T. Real-time feedback promotes energy conservation in the absence of volunteer selection bias and monetary incentives. Nat. Energy 2019, 4, 35-41. [CrossRef]

82. Strauss, A.; Corbin, J. Basics of Qualitative Research; Sage publications: Saunders Oaks, CA, USA, 1990.

83. Willig, C. Introducing Qualitative Research in Psychology; McGraw-Hill Education (UK): Maidenhead, UK, 2013.

84. Glaser, B.G.; Strauss, A.L. Discovery of Grounded Theory: Strategies for Qualitative Research; Routledge: Abingdon, UK, 2017.

85. Bucher, D.; Cellina, F.; Mangili, F.; Raubal, M.; Rudel, R.; Rizzoli, A.E.; Elabed, O. Exploiting fitness apps for sustainable mobility-challenges deploying the GoEco! app. In Proceedings of the ICT for Sustainability (ICT4S), Amsterland, The Netherland, 29 August-1 September 2016.

86. Russell, S.J.; Norvig, P. Artificial Intelligence: A Modern Approach, 3rd ed.; Pearson Education Limited: Upper Saddle River, NJ, USA, 2010.

87. Bucher, D.; Mangili, F.; Cellina, F.; Bonesana, C.; Jonietz, D.; Raubal, M. From location tracking to personalized eco-feedback: A framework for geographic information collection, processing and visualization to promote sustainable mobility behaviors. Travel Behav. Soc. 2019, 14, 43-56. [CrossRef]

88. Tuchschmid, M.; Halder, M.; Bauer, C. mobitool-Grundlagenbericht. In Hintergrund, Methodik $\mathcal{E}$ Emissionsfaktoren; Schweizerische Bundesbahnen (SBB): Bern, Switzerland; Swisscom: Bern, Switzerland; BKW, öbu: Bern, Switzerland, 2010.

89. Johnson, M.K.; Hasher, L. Human learning and memory. Annu. Rev. Psychol. 1987, 38, 631-668. [CrossRef] [PubMed]

90. Kantola, S.J.; Syme, G.J.; Campbell, N.A. Cognitive dissonance and energy conservation. J. Appl. Psychol. 1984, 69, 416-421. [CrossRef]

91. Deci, E.L. Effects of externally mediated rewards on intrinsic motivation. J. Personal. Soc. Psychol. 1971, 18, 105-115. [CrossRef]

92. Allcott, H.; Rogers, T. The short-run and long-run effects of behavioral interventions: Experimental evidence from energy conservation. Am. Econ. Rev. 2014, 104, 3003-3037. [CrossRef]

93. Bundesamt für Raumentwicklung. ÖV-Güteklassen-Berechnungsmethodik ARE; Technical Report; Eidgenössisches Departement für Umwelt, Verkehr, Energie und Kommunikation UVEK: Bern, Switzerland, 2011. 
94. Avineri, E. On the use and potential of behavioural economics from the perspective of transport and climate change. J. Transp. Geogr. 2012, 24, 512-521. [CrossRef]

95. Metcalfe, R.; Dolan, P. Behavioural economics and its implications for transport. J. Transp. Geogr. 2012, 24, 503-511. [CrossRef]

96. Frederiks, E.R.; Stenner, K.; Hobman, E.V. Household energy use: Applying behavioural economics to understand consumer decision-making and behaviour. Renew. Sustain. Energy Rev. 2015, 41, 1385-1394. [CrossRef]

97. Fraternali, P.; Herrera, S.; Novak, J.; Melenhorst, M.; Tzovaras, D.; Krinidis, S.; Rizzoli, A.E.; Rottondi, C.; Cellina, F. enCOMPASS-An integrative approach to behavioural change for energy saving. In Proceedings of the Global Internet of Things Summit (GIoTS), Geneva, Switzerland, 6-9 June 2017; pp. 1-6.

98. UNDP-United Nations Development Programme. Human Development Indices and Indicators, 2018 Statistical Update; Technical Report; United Nations Development Programme: New York, NY, USA, 2018.

99. Habibipour, A.; Bergvall-Kareborn, B.; Ståhlbröst, A. How to sustain user engagement over time: A research agenda. In Proceedings of the 22nd Americas Conference on Information Systems (AMCIS 2016), San Diego, CA, USA, 11-14 August 2016.

100. Heiskanen, E.; Johnson, M.; Robinson, S.; Vadovics, E.; Saastamoinen, M. Low-carbon communities as a context for individual behavioural change. Energy Policy 2010, 38, 7586-7595. [CrossRef]

101. Wemyss, D.; Castri, R.; Cellina, F.; De Luca, V.; Lobsiger-Kägi, E.; Carabias, V. Examining community-level collaborative vs. competitive approaches to enhance household electricity-saving behavior. Energy Effic. 2018, 11, 2057-2075. [CrossRef]

(C) 2019 by the authors. Licensee MDPI, Basel, Switzerland. This article is an open access article distributed under the terms and conditions of the Creative Commons Attribution (CC BY) license (http:/ / creativecommons.org/licenses/by/4.0/). 